\title{
Measurement of Magnetic Field Properties of a 3.0 T/m Air-Core HTS Quadrupole Magnet and Optimal Shape Design to Increase the Critical Current Reduced by the Incident Magnetic Field
}

\author{
Yojong Choi ${ }^{1}{ }^{1}$, Junseong Kim ${ }^{1}$, Geonwoo Baek ${ }^{1}$, Seunghak Han ${ }^{1}$, Woo Seung Lee ${ }^{2}$ and \\ Tae Kuk Ko ${ }^{1, *}$ \\ 1 School of Electrical and Electronic Engineering, Yonsei University, Seoul 30722, Korea; \\ cyj7287@yonsei.ac.kr (Y.C.); junsung0616@yonsei.ac.kr (J.K.); bgw03@naver.com (G.B.); \\ seunghak90@yonsei.ac.kr (S.H.) \\ 2 Francis Bitter Magnet Laboratory, Plasma Science and Fusion Center, Massachusetts Institute of Technology, \\ Cambridge, MA 02139, USA; wooseung@mit.edu \\ * Correspondence: tkko@yonsei.ac.kr; Tel.: +82-2-2123-2772
}

Received: 16 February 2020; Accepted: 3 March 2020; Published: 7 March 2020

\begin{abstract}
Air-core high-temperature superconducting quadrupole magnets (AHQMs) differ from conventional iron-core quadrupole magnets, in that their iron cores are removed, and instead high-temperature superconductors (HTSs) are applied. The high operating temperature and high thermal stability of HTS magnets can improve their thermodynamic cooling efficiency. Thus, HTS magnets are more suitable than low temperature superconducting magnets for withstanding radiation and high heat loads in the hot cells of accelerators. AHQMs are advantageous because they are compact, light, and free from the hysteresis of ferromagnetic materials, due to the removal of the iron-core. To verify the feasibility of the use of AHQMs, we designed and fabricated a $3.0 \mathrm{~T} / \mathrm{m}$ AHQM. The magnetic field properties of the fabricated AHQM were evaluated. Additionally, the characteristics of the air-core model and iron-core model of $9.0 \mathrm{~T} / \mathrm{m}$ were compared in the scale for practical operation. In comparison with the iron-core model, AHQM significantly reduces the critical current $\left(\mathrm{I}_{\mathrm{C}}\right)$ due to the strong magnetic field inside the coil. In this study, a method for the accurate calculation of $\mathrm{I}_{\mathrm{C}}$ is introduced, and the calculated results are compared with measured results. Furthermore, the optimal shape design of the AHQM to increase the critical current is introduced.
\end{abstract}

Keywords: air-core quadrupole magnet; critical current degradation; heavy-ion accelerator; high-temperature superconductor; iron-core quadrupole magnet; optimum shape design

\section{Introduction}

Generally, quadrupole magnets for beam focusing in accelerators are manufactured using low temperature superconductors (LTSs) [1]. However, the LTS, which has a low thermal stability, is not suitable for use in the in-flight fragment (IF) pre-separator of a heavy-ion accelerator, because there is a radiation region that causes a high heat load [2,3]. In comparison with LTSs operating in a liquid helium environment, the high operating temperature and high thermal stability of high-temperature superconductors (HTSs) can improve the thermodynamic cooling efficiency [4]. The removal of the heat load at $40 \mathrm{~K}$ is approximately 10 times more efficient than that at $4-5 \mathrm{~K}[5,6]$. Thus, HTS magnets are more suitable than LTS magnets in withstanding radiation and high heat loads in the hot cells of accelerators. 
Because of these advantages, including the thermal stability of HTS, as an example, it has been reported that in the Rare Isotope Science Project for the construction of a heavy-ion accelerator called RAON in Korea, six HTS quadrupole magnets will be installed in succession for beam focusing at the front region of the IF pre-separator [7]. Additionally, HTS quadrupole magnets using air-cores have many advantages for heavy-ion accelerator applications, because of the elimination of the iron-core of the conventional HTS quadrupole magnet. Quadrupole magnets with a removed iron-core are advantageous because of their compactness and lightweight, and they are free from the hysteresis of ferromagnetic materials. Therefore, a new quadrupole magnet has been proposed with two differences [8]: replacing the LTS with the HTS wires, and removing the iron-core. As an initial study to replace the existing quadrupole magnets, the effects of the manufacturing error, and the comparison of the characteristics with the iron core, were performed $[9,10]$. However, no case has been reported on the construction and operation of quadrupole magnets using HTS wires detached from the iron-core. Therefore, research should precede the manufacturing of air-core quadrupole magnets, and the analysis of the magnetic field properties based on the magnetic field measurements. To verify the feasibility of the air-core HTS quadrupole magnet, we designed and fabricated an air-core high-temperature superconducting quadrupole magnet with a field gradient of $3.0 \mathrm{~T} / \mathrm{m}$, an effective length of more than $200 \mathrm{~mm}$, and a uniformity of less than $1 \%$. We also fabricated a field mapper to measure the field quality of an air-core HTS quadrupole magnet. We measured the magnetic field at the measuring points of reference in a radius of $70 \mathrm{~mm}$ inside the beam tube, and calculated the magnetic field properties. We confirmed that the fabricated air-core HTS quadrupole magnet meets the required magnetic field quality.

However, in our previous comparative studies, we found that the air-core model has a stronger magnetic field applied to the coil, where the superconducting wire is located compared to the iron core model [10]. The air-core HTS quadrupole magnet, which must satisfy the required field characteristics only by the HTS wire, generates a larger magnetic field inside the superconducting coil than the iron-core model. Because the 2G HTS wire reduces the critical current via the incident magnetic field, the critical current may be considerably reduced because of the strong magnetic field generated inside the coil of the air-core model. Because the critical current of the superconducting tape is inversely proportional to the operating temperature, a method to lower the operating temperature is generally selected to increase the critical current [11]. The operating temperature can be further reduced by installing a cryocooler in the magnet with the use of cold refrigerant [12-14]. However, facilities that operate accelerators provide a certain cooling temperature by using instruments, such as a cryocooler, and require considerable effort to further reduce the operating temperature. For example, the RAON in Korea has adopted the circulating gas helium cooling method, and has set the nominal operation temperature to $40 \mathrm{~K}[4,6,15]$. Therefore, designing the shape and arrangement of the quadrupole magnet for a high critical current is required to secure the margin of the operation current and to increase operational safety. Because of the laminated structure of the 2G HTS-tape coated conductor, the critical current reduced by the magnetic field is affected, not only by the strength of the magnetic field, but also by the angle [11,16]. In the 2G HTS wire, the perpendicular magnetic field has a greater influence on the reduction of the critical current than the parallel magnetic field. Conventional HTS wires have the most significant reduction in the critical current when a perpendicular magnetic field is applied. Therefore, in applications using HTS wires, the lowest critical current in all sections is evaluated as the critical current of the entire magnet, because the magnet is continuously winding the HTS tape. Therefore, in general, while predicting the critical current of superconducting magnets, including iron-core quadrupole magnets, only the perpendicular magnetic field is considered $[6,7,10]$. However, the recently developed 2G HTS tapes have different critical current characteristics than those of conventional 2G HTS tapes, because of the introduction of an artificial pinning center to improve its magnetic field performance $[17,18]$. For example, SuNAM 2G HTS tapes have a minimum critical current at the incidence angle of $30-70^{\circ}$, and not $90^{\circ}[17,19]$. In particular, the air-core HTS quadrupole 
magnets, which are arranged for the required field properties, generate a stronger parallel magnetic field than the perpendicular magnetic field in the coil in which the superconducting wire is placed.

Therefore, both the magnetic field strength and angle must be considered to accurately predict the reduction of the critical current of the air-core HTS quadrupole magnet. In this paper, we propose a method of calculating the critical current suitable for the air-core model. The calculated critical current was compared to the measured critical current using a $3.0 \mathrm{~T} / \mathrm{m}$ HTS quadrupole magnet, in order to ensure the reliability of the calculated critical current, and it was confirmed that it fits well. Recently, a prototype of a $9.0 \mathrm{~T} / \mathrm{m}$ HTS quadrupole magnet using iron-core was developed and tested at the Institute for Basic Science (IBS) and Korea Electrotechnology Research Institute (KERI) [6]. We designed a $9.0 \mathrm{~T} / \mathrm{m}$ class air-core HTS quadrupole magnet with the same specifications as the iron-core HTS quadrupole magnet, and the differences between the air-core model and the iron-core model were compared. In this study, the characteristics, such as magnetic field properties and mechanical stress, including critical current, were compared and analyzed. Comparable results show that the air-core model is suitable to replace the iron-core model; however, the critical current of the air-core model is significantly reduced, eliminating the margin of the operational current at an operating temperature of $40 \mathrm{~K}$. Therefore, we also designed the new optimal shape of the $9.0 \mathrm{~T} / \mathrm{m}$ air-core HTS quadrupole magnet to minimize the critical current degradation, considering both the angle and the intensity of the magnetic field. The critical currents of the air-core and iron-core HTS quadrupole magnet in the temperature range of 30-60 K were compared, and the operating current margin was evaluated for each operating temperature.

In this study, an air-core HTS quadrupole magnet is successfully constructed and tested to validate its applicability. Furthermore, a critical current calculation method suitable for the air-core model is proposed and compared with the experimental results. An optimal design method for increasing the critical current of an air-core model with a lower critical current compared to the iron-core model is introduced. By applying the proposed design method, it is expected that the air-core HTS quadrupole magnet can achieve a higher critical current margin and improve operation stability.

Section 2 demonstrates the feasibility of the air-core model through the fabrication and testing of a $3.0 \mathrm{~T} / \mathrm{m}$ air-core HTS quadrupole magnet. Section 3.1 proposes a critical current calculation method for the air-core model. Section 3.2 compares and verifies the proposed critical current calculation method with the experimental results of the manufactured DPC. Section 4 compares several characteristics of the air-core model with the $9.0 \mathrm{~T} / \mathrm{m}$ iron-core HTS quadrupole magnet developed as a prototype. Section 5.1 introduces the optimization algorithm for air-core quadrupole magnets to maximize critical current. Section 5.2 analyzes the characteristics of the newly optimized air-core model. Section 6 contains the conclusion and discussion.

\section{Test of 3.0 T/m Air-Core HTS Quadrupole Magnet}

\subsection{Harmonic Coefficients and Major Magnetic Properties}

Considering the boundary conditions of the actual quadrupole magnet, the solution of Laplace's equation in the cylindrical coordinate system is given by the following equation [20]:

$$
V(\rho, \varphi, z)=\sum_{n=0}^{\infty} \sum_{m=0}^{\infty}\left[\frac{\rho_{0}}{n+2 m}\left(\frac{\rho}{\rho_{0}}\right)^{n+2 m}\left(s_{n, m}(z) \cos (n \varphi)+l_{n, m}(z) \sin (n \varphi)\right)\right],
$$

where $\rho$ is the radial distance, $\varphi$ is the angular coordinate, $z$ is the height and $\rho_{0}$ is the reference radius. $l_{n, m}(z)$ and $s_{n, m}(z)$ are the normal and skew components, respectively, and contain information 
regarding the coil shape and the position. From the gradient in Equation (1), the magnetic flux density of the cylindrical coordinate system is obtained as follows [20]

$$
\begin{gathered}
B_{\rho}(\rho, \varphi, z)=\sum_{n=0}^{\infty} \sum_{m=0}^{\infty}\left[\left(\frac{\rho}{\rho_{0}}\right)^{n+2 m-1}\left(s_{n, m}(z) \cos (n \varphi)+l_{n, m} \sin (n \varphi)\right]\right. \\
B_{\varphi}(\rho, \varphi, z)=\sum_{n=0}^{\infty} \sum_{m=0}^{\infty}\left[\frac{\rho_{0}}{n+2 m}\left(\frac{\rho}{\rho_{0}}\right)^{n+2 m}\left(-n s_{n, m}(z) \sin (n \varphi)+n l_{n, m} \cos (n \varphi)\right)\right]
\end{gathered}
$$

$B_{\rho}$ and $B_{\varphi}$ are the magnetic flux density components in the radial and azimuthal directions, respectively. In the quadrupole magnet, one of the skew or normal terms can be excluded by the placement of each pole. The magnetic field is represented by its periodic function with respect to the azimuthal angle. The magnetic field for the azimuthal angle, measured at the reference radius, is the main component in which the secondary harmonics is used for focusing the beams of the quadrupole magnet. The magnetic field properties of the quadrupole magnet are generally evaluated using three factors-gradient, uniformity and effective length-which are represented using Equations (4)-(6), respectively [20].

$$
\begin{gathered}
G=\frac{B_{\rho 2}\left(\rho_{0}, z=0\right)}{\rho_{0}} \\
U_{\rho n}=\frac{\int_{-\infty}^{\infty} B_{\rho n}\left(\rho_{0}, z\right) d z}{\int_{-\infty}^{\infty} B_{\rho 2}\left(\rho_{0}, z\right) d z},(3-D) \\
L_{e f f}=\frac{\int_{-\infty}^{\infty} B_{\rho 2}\left(\rho_{0}, z\right) d z}{B_{\rho 2}\left(\rho_{0}, z=0\right)}
\end{gathered}
$$

The gradient representing the slope of the magnetic field from the reference radius to the center represents the magnetic strength of the quadrupole magnet. Uniformity is used to evaluate the homogeneity of the magnetic field, and is classified by each order. The main uniformities in the air-core quadrupole magnet are the 6th and 10th order components. The effective length represents the influence of the secondary component, which is the main harmonic of the quadrupole magnet, on the direction of the transporting beam trajectory.

\subsection{Fabrication of $3.0 \mathrm{~T} / \mathrm{m}$ Air-Core HTS Quadrupole Magnet}

To validate the design and operation of the air-core HTS quadrupole magnet, an air-core HTS quadrupole magnet with a gradient of $3.0 \mathrm{~T} / \mathrm{m}$, an effective length of more than $200 \mathrm{~mm}$ and a uniformity of less than $1 \%$, was designed and fabricated. Figure 1a shows the coil arrangement of the designed quadrupole magnet. Each pole consists of two double-pancake coils (DPCs), and each DPC consists of two racetrack-type single-pancake coils (SPCs). Figure 1 shows the SPC configuration parameters and the location parameters of the DPCs used in the design. Table 1 summarizes the design parameters for each SPC. Turns of all SPCs were insulated using stainless steel (SUS) tape, which is suitable for withstanding high radiation. Figure 2a shows the co-winding process of the HTS tape with the SUS tape. Approximately 2-km long HTS and SUS tapes were used for the 16-SPC winding. Figure $2 \mathrm{~b}$ shows a DPC module containing two SPCs, the current lead, and bobbin plates. The quadrupole magnet assembled on the beam tube is shown in Figure 2c. To eliminate field changes caused by the magnetization of the surrounding components, bobbin plates and beam tubes were fabricated of aluminum and SUS, respectively, with nonmagnetic properties. The surface of the bobbin plate was anodized to insulate the bobbin plate fabricated by aluminum. 


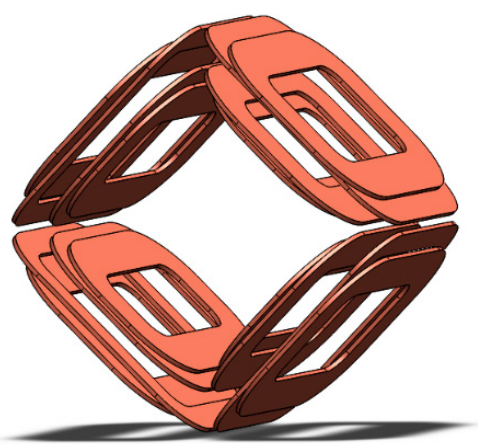

(a)

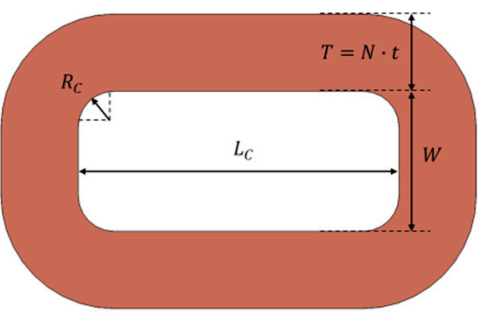

(b)

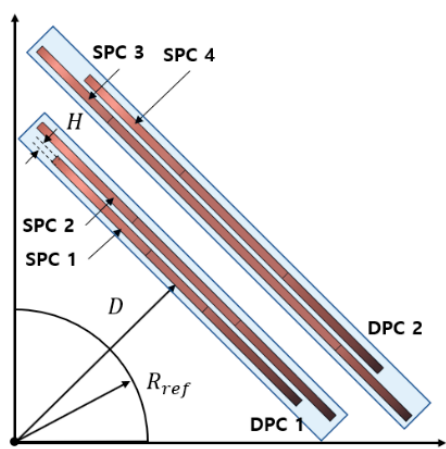

(c)

Figure 1. (a) Solid view of the designed quadrupole magnet; (b) Design parameters for the single-pancake coil (SPC); (c) Design parameters for position of the double-pancake coil (DPC).

Table 1. Design parameters of the $3.0 \mathrm{~T} / \mathrm{m}$ air-core high-temperature superconductors (HTSs) quadrupole magnet.

\begin{tabular}{|c|c|c|c|c|}
\hline Design Parameter & SPC 1 & SPC 2 & SPC 3 & SPC 4 \\
\hline HTS tape width $\left(\mathrm{H}_{1}\right)$ & \multicolumn{4}{|c|}{$4.1 \mathrm{~mm}$} \\
\hline SUS tape width $\left(\mathrm{H}_{2}\right)$ & \multicolumn{4}{|c|}{$4.2 \mathrm{~mm}$} \\
\hline HTS tape thickness $\left(t_{1}\right)$ & \multicolumn{4}{|c|}{$0.14 \mathrm{~mm}$} \\
\hline SUS tape thickness $\left(t_{2}\right)$ & \multicolumn{4}{|c|}{$0.08 \mathrm{~mm}$} \\
\hline Distance from center (D) & $96.4 \mathrm{~mm}$ & $102.5 \mathrm{~mm}$ & $128 \mathrm{~mm}$ & $134 \mathrm{~mm}$ \\
\hline Coil width $(\mathrm{W})$ & $78 \mathrm{~mm}$ & $109 \mathrm{~mm}$ & $193 \mathrm{~mm}$ & $109 \mathrm{~mm}$ \\
\hline Turns (N) & 195 turn & 200 turn & 125 turn & 200 turn \\
\hline Radius of curve $\left(\mathrm{R}_{\mathrm{C}}\right)$ & \multicolumn{4}{|c|}{$20 \mathrm{~mm}$} \\
\hline Coil length $\left(\mathrm{L}_{\mathrm{C}}\right)$ & \multicolumn{4}{|c|}{$179 \mathrm{~mm}$} \\
\hline
\end{tabular}

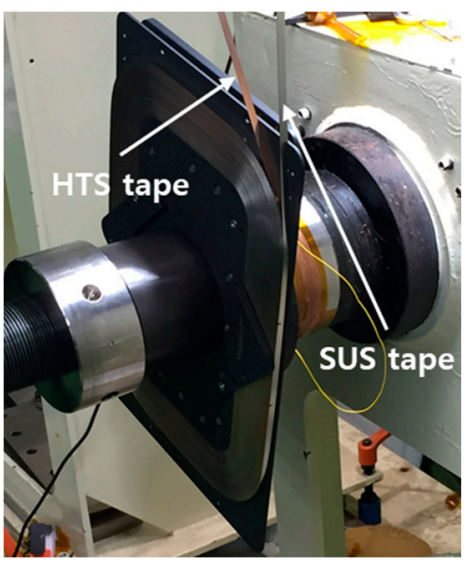

(a)

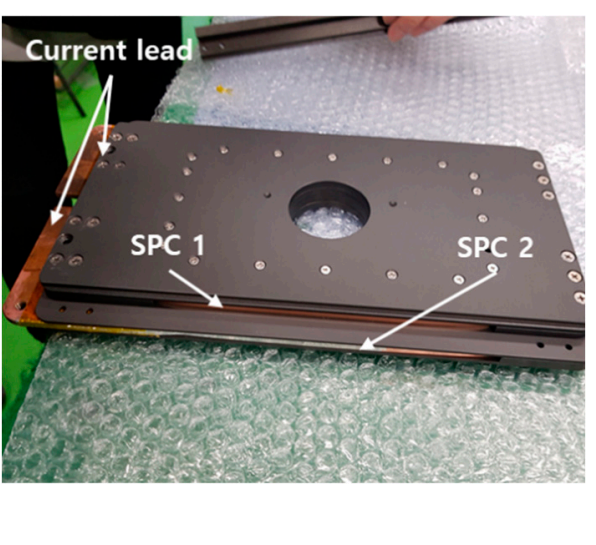

(b)

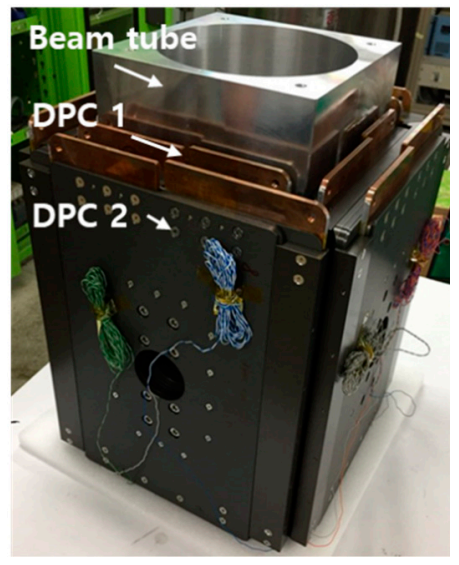

(c)

Figure 2. Manufacturing process of the quadrupole magnet. (a) Co-winding process of the HTS tape with the stainless steel (SUS) tape; (b) Manufactured DPC module containing two SPCs, current lead and bobbin plates; (c) Air-core quadrupole magnet assembled on beam tube.

\subsection{Experimental Setup for the Magnetic Field Measurement of the Air-Core HTS Quadrupole Magnet}

A mapper using a stepping motor was fabricated to measure the magnetic field of the $3.0 \mathrm{~T} / \mathrm{m}$ air-core HTS quadrupole magnet. Figure 3a shows a fabricated mapper with three axes. The mapper is designed to be moved to the $\mathrm{x}, \mathrm{y}$ and $\mathrm{z}$ axes using cartesian coordinates, and it is possible to measure the magnetic field densities in three directions $\left(B_{X}, B_{Y}, B_{Z}\right)$ using a 3-axis hall probe located at the end of probe arm. Five hundred mapping points were set in the azimuth range from $0^{\circ}$ to $360^{\circ}$ at $15^{\circ}$ intervals and in the $\mathrm{z}$ range from -180 to +200 at $20-\mathrm{mm}$ intervals. Figure $3 \mathrm{~b}$ shows the mapping 
points used for magnetic field measurements. The measured magnetic fields were converted to the radial direction components $\mathrm{B}_{\rho}$ by performing calculations in the cartesian coordinate system to the cylindrical coordinate system.

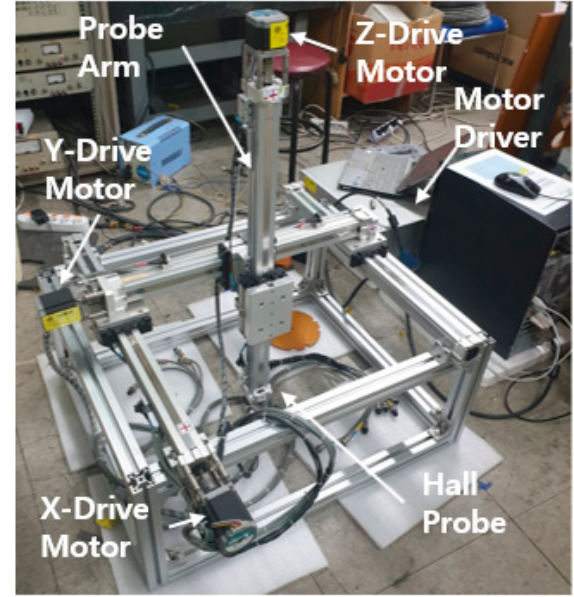

(a)

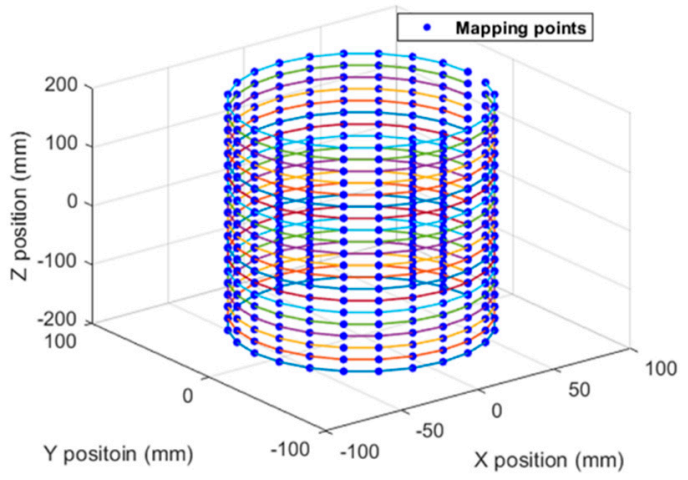

(b)

Figure 3. (a) Manufactured mapper with three axes; (b) Mapping point set for magnetic field measurement.

The operating current of the fabricated $3.0 \mathrm{~T} / \mathrm{m}$ air-core HTS quadrupole magnet was set to $50 \mathrm{~A}$, and all coils were connected in series to conduct the same current. A constant current source (HP 6671A) was used to supply a constant current, and a high-speed data acquisition system for the voltage measurement of the Hall probe was connected to the mapper. A cryostat filled with liquid nitrogen was maintained at a temperature of $77 \mathrm{~K}$ to provide a cooling temperature below the critical temperature of the HTS wire. Furthermore, a continuous liquid nitrogen supply device was constructed to replenish the evaporated liquid refrigerant due to the heat generated during the current operation.

\subsection{Measurement of the Magnetic Field Properties}

Figure $4 \mathrm{a}$ shows the measured and calculated $\mathrm{B}_{\rho}$ values for each azimuthal angle at the $\mathrm{z}$ position in the negative direction, and Figure $4 \mathrm{~b}$ shows the measured and calculated $\mathrm{B}_{\rho}$ values for each azimuthal angle at the $\mathrm{z}$ position in the positive direction. The measurement results were found to agree well with the calculation results; however, errors were found at the z positions of $100 \mathrm{~mm}$ and $120 \mathrm{~mm}$. At some points, the measured $B_{\rho}$ values in the negative direction were larger than the calculated $B_{\rho}$ values; however, the measured $B_{\rho}$ values in the positive direction were smaller than the calculated $B_{\rho}$ values. This difference is presumably due to the measurement position error of the mapper. However, in the calculation of the magnetic field properties, the positive and negative measurement results are integrated over the entire range, and this error does not affect the field property evaluation. Additionally, the magnetic field density measured at $z=0$ was higher than the calculated results. Therefore, the field gradient using the measured value was slightly higher than the calculated result. Figure 5 shows the field gradient and major harmonics evaluated along the $\mathrm{z}$ direction. The difference in the field gradient is assumed to be due to the manufacturing error and the mapper measurement error. However, in the case of the air-core quadrupole magnet, the field gradient can be adjusted without changing the uniformity and effective length by adjusting the operating current. The changes in the field properties with operating current are introduced in Section 4. 

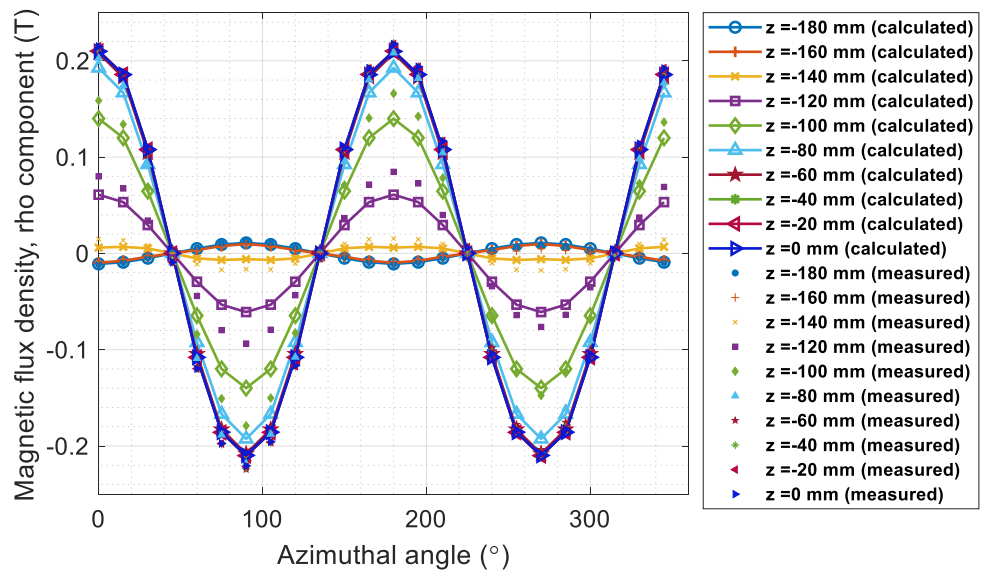

(a)
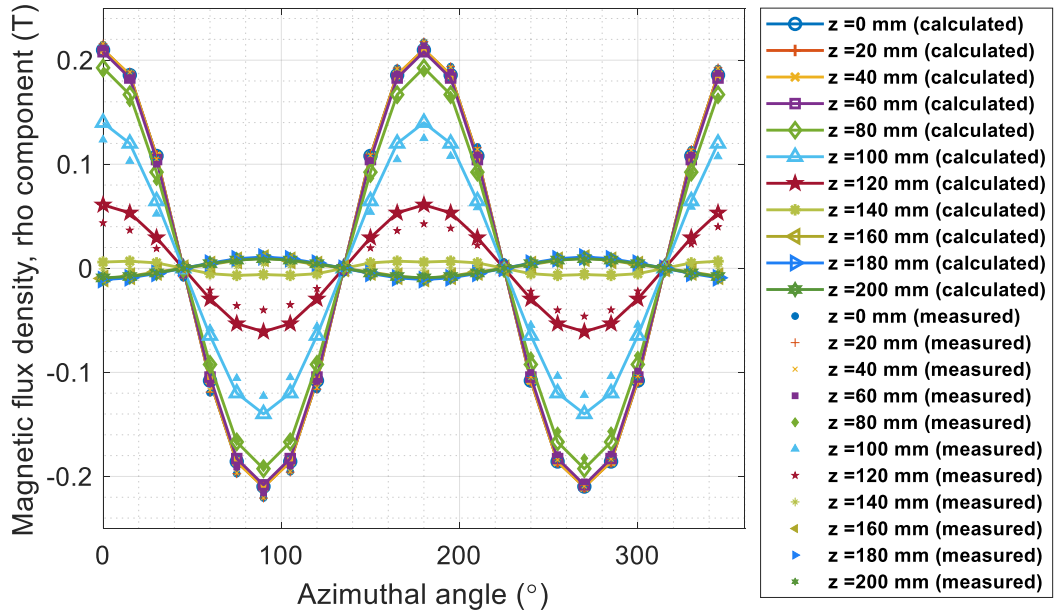

(b)

Figure 4. Comparison of the calculated and measured values of magnetic flux density. (a) $\mathrm{Z}$ range: from -180 to 0 at $20 \mathrm{~mm}$ intervals; (b) Z range: from 0 to +200 at $20 \mathrm{~mm}$ intervals.

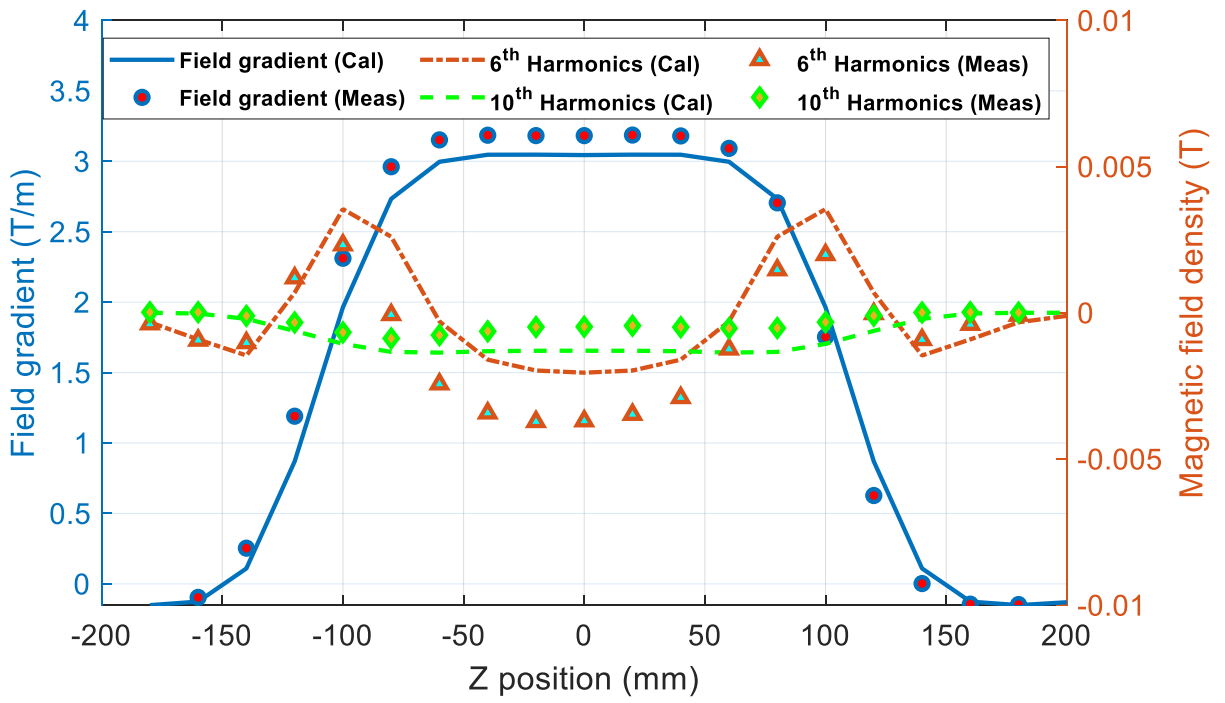

Figure 5. Field gradient and major 6th and 10th harmonics according to z position.

In Figure 6, the 3D uniformity of each harmonics order is compared. The main uniformity of the quadrupole magnet is evaluated at the 6th and 10th harmonics. In the design results, only the 6th and 
10th order uniformity is shown, whereas the measured uniformity is shown for various orders, as well as for the 6 th and 10 th order components. However, all uniformities were rated at less than $1 \%$, and met the design target range. Table 2 compares the magnetic properties evaluated from the design and measurement results. Despite some manufacturing errors, all magnetic properties were found to meet the design objectives.

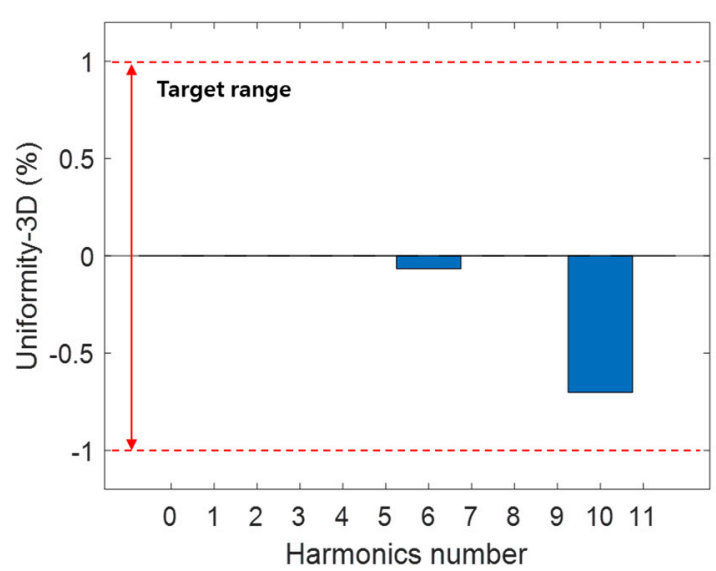

(a)

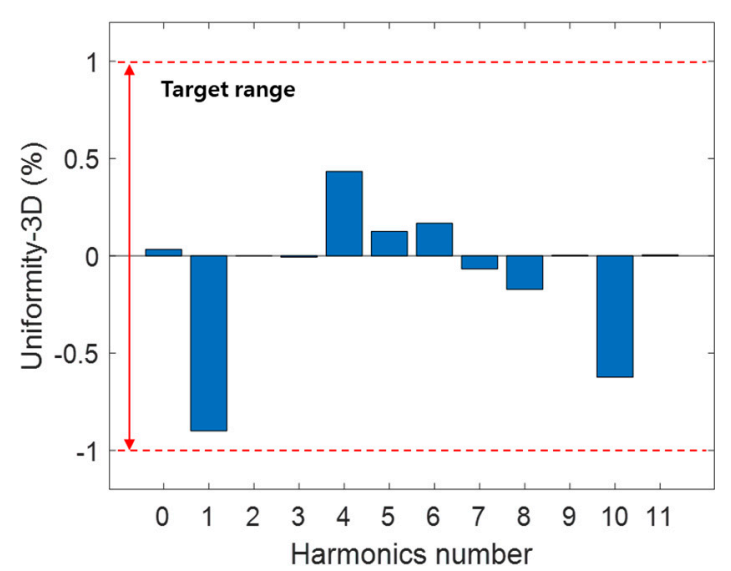

(b)

Figure 6. Three dimensional (3D) uniformity evaluation according to harmonic order. (a) Designed uniformity; (b) measured uniformity.

Table 2. Evaluation of magnetic field properties of the $3.0 \mathrm{~T} / \mathrm{m}$ air-core HTS quadrupole magnet.

\begin{tabular}{cccc}
\hline Magnetic Properties & Target & Design & Measurement \\
\hline Gradient $(\mathrm{G})$ & $\geq 3.0 \mathrm{~T} / \mathrm{m}$ & $3.044 \mathrm{~T} / \mathrm{m}$ & $3.127 \mathrm{~T} / \mathrm{m}$ \\
Effective length $\left(\mathrm{L}_{\mathrm{eff}}\right)$ & $\geq 200 \mathrm{~mm}$ & $210.4624 \mathrm{~mm}$ & $209.9693 \mathrm{~mm}$ \\
6th uniformity $\left(\mathrm{U}_{6}\right)$ & $\leq 1 \%$ & $-0.0629 \%$ & $0.1673 \%$ \\
10th uniformity $\left(\mathrm{U}_{10}\right)$ & $\leq 1 \%$ & $-0.7027 \%$ & $-0.6242 \%$ \\
\hline
\end{tabular}

\section{Calculation of Critical Current Reduced by Incident Magnetic Field}

\subsection{Critical Current Reduced by Incident Magnetic Field}

The 2G HTS tape reduces the critical current by the incident magnetic field, and is affected by the strength and angle of the incident magnetic field. In general, the 2G HTS tape reduces the critical current most when a perpendicular magnetic field is applied. However, the recently developed $2 \mathrm{G}$ HTS tape reduces the critical current in the incident magnetic field condition to $30^{\circ}-70^{\circ}$, instead of the perpendicular magnetic field condition, by introducing an artificial pinning center to improve the magnetic field performance under a high magnetic field.

Figure 7a shows the measured critical current of $4 \mathrm{~mm}$ SuNAM REBCO tapes at $40 \mathrm{~K}$. The lowest critical current for each incident magnetic field intensity is depicted by a blue circle. The measured critical current is the lowest in the range of $30-70^{\circ}$, and the stronger the intensity of the incident magnetic field, the greater the influence of the parallel magnetic field components on the reduction of the critical current. Additionally, air-core HTS quadrupole magnets are applied with a larger magnetic field in the parallel direction than in the perpendicular direction. Therefore, as the required magnetic field strength of the air-core HTS quadrupole magnet increases, the critical current reduction for all angles should be considered. The linear interpolation method was used to calculate the critical current over all angles and intensity ranges. Figure $7 \mathrm{~b}$ shows the critical currents fitted using this linear interpolation method. The critical current was normalized by dividing it by the critical current $\mathrm{I}_{\mathrm{C} 0}$ when no magnetic field was applied. These normalized critical currents can then be applied to HTS tapes with various critical currents. 


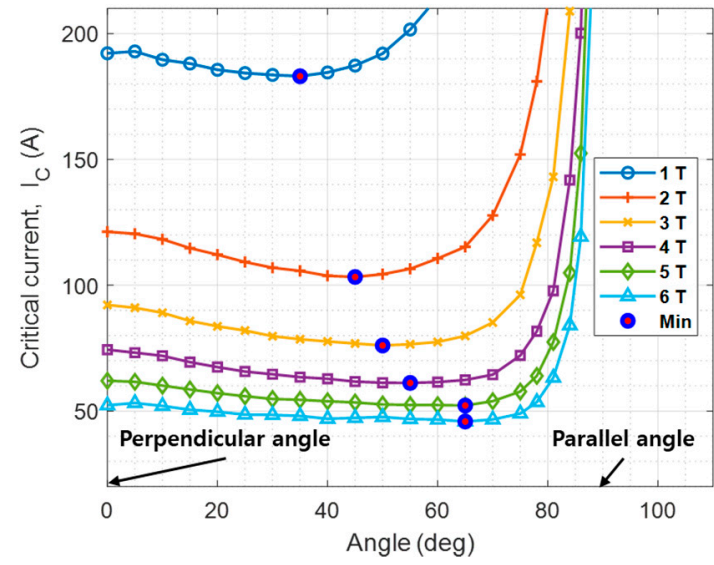

(a)

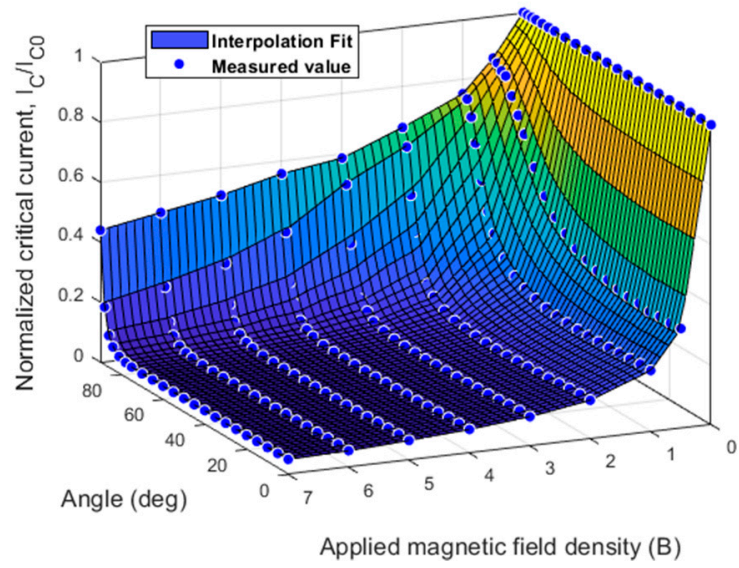

(b)

Figure 7. $\mathrm{I}_{\mathrm{C}}(\mathrm{B}, \theta)$ of a $4 \mathrm{~mm}$ SuNAM REBCO tape at $40 \mathrm{~K}$. (a) Critical current according to angle and applied magnetic field; and (b) linear interpolation using the measured values.

Figure 8 shows the divided sections to obtain the critical current of the HTS tape from the observed field strength and angle. Because the calculated or measured magnetic field values are not continuous but discrete, the critical current density for each section is numerically integrated using the strength and angular components of the magnetic field generated at each point. The critical current of the HTS tape is calculated using Equations (7)-(10), and the lowest critical current calculated by extending to all areas of the magnet can be predicted as the critical current of the quadrupole magnet. The critical current calculated at a fixed current is only related to the critical current margin. For a magnetic field that changes with the operating current, the critical current for the operating current must be calculated repeatedly. The critical current is calculated by increasing the operating current, and the calculated critical current is evaluated as the exact critical current of the quadrupole magnet when the operating current matches the critical current calculated.
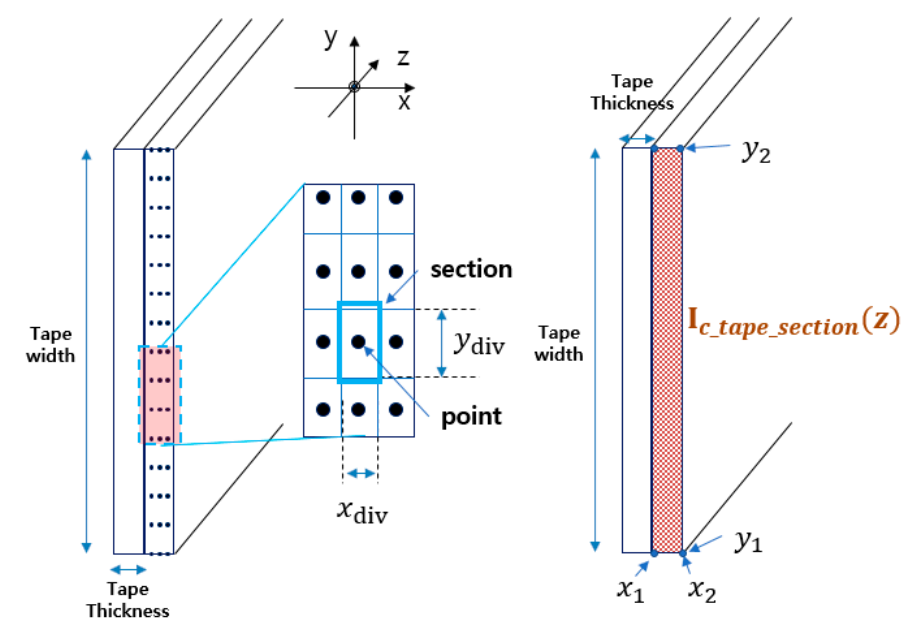

Figure 8. Section division for calculating critical current of the HTS tape section.

$$
\begin{aligned}
& I_{\text {C_point }}(x, y, z)=\delta_{\text {point }}(B, \theta) \cdot I_{c 0} \\
& J_{\mathcal{C}_{-} \text {section }}(x, y, z)=\frac{I_{\text {c_point }}(x, y, z)}{x_{\text {div }} \cdot y_{\text {div }}} \\
& I_{\text {C_tape_section }}(z)=\int_{x_{1}}^{x_{2}} \int_{y_{1}}^{y_{2}} J_{\mathcal{C}_{\text {_section }}}(x, y, z) d y d x
\end{aligned}
$$




$$
I_{C_{-} \text {tape }}=\min \left(I_{C_{-} \text {tape_section }}(z)\right),
$$

where $I_{C}, I_{C 0}$, and $J_{C}$ are the critical current calculated, critical current at $77 \mathrm{~K}$ when no magnetic field is applied, and the critical current density, respectively. $\delta$ is the normalized critical current obtained from the interpolation fitting data.

\subsection{Critical Current of Two DPCs Fabricated for 3.0 T/m Air-Core Quadrupole Magnet}

Because of the structural symmetry of the quadrupole magnets, all areas of the quadrupole magnets can be interpreted by interpreting $1 / 16$ th of the quadrupole magnets. In the $1 / 16$ th analysis area, the SPC is divided into a half long cuboid part, half short cuboid part, and curved part. Figure 9 shows the area for calculating the critical current and the parts of each divided SPC.

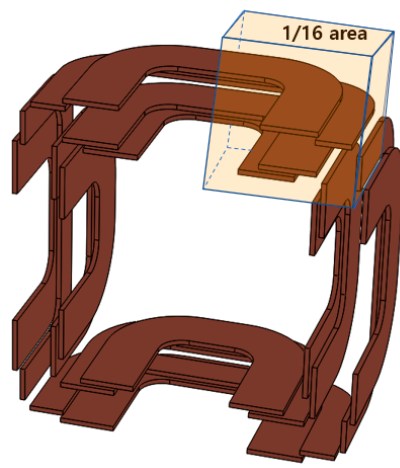

(a)

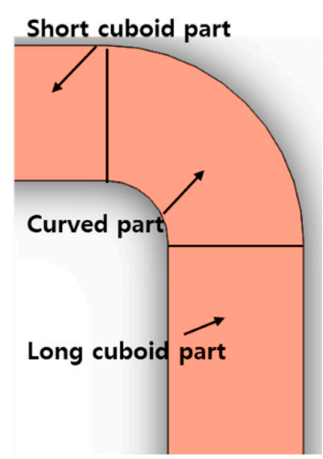

(b)

Figure 9. (a) Critical current calculation area for air-core HTS quadrupole magnet; (b) parts of each divided SPC.

Figure 10a shows the minimum critical current of each SPC calculated with increasing operating current. The black solid load line is drawn to find the current whose operating current matches the minimum critical current. The minimum critical current calculated when considering only the magnetic field incident in the perpendicular direction is different from that calculated by considering the magnetic fields of all angular components. The critical current of each DPC manufactured for the $3.0 \mathrm{~T} / \mathrm{m}$ air-core quadrupole magnet was measured in a bath of liquid nitrogen. Figure 10b shows the I-V curves measured at the two DPCs. The lengths of the HTS wire used in the windings of DPC 1 and DPC 2 were $256 \mathrm{~m}$ and $236 \mathrm{~m}$, respectively, and the quench voltage was determined by the $1 \mu \mathrm{V} / \mathrm{cm}$ criterion.

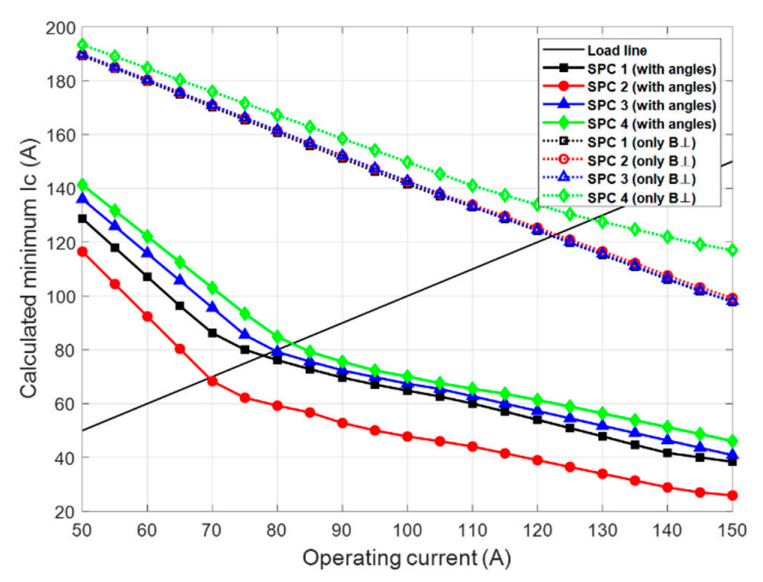

(a)

Figure 10. Cont. 


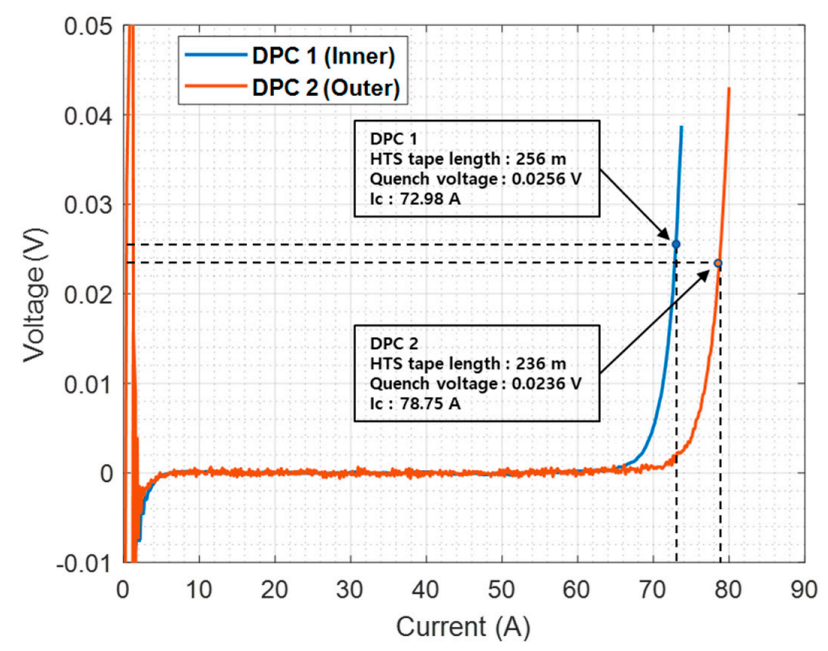

(b)

Figure 10. Critical current of each DPC. (a) Minimum critical current calculated for each operating current; (b) critical current measurement result.

Table 3 summarizes the calculated and measured results of the critical currents of DPC 1 and DPC 2. Because DPC 1 consists of SPC 1 and SPC 2, and DPC 2 consists of SPC 3 and SPC 4, the lower critical current of the two SPCs is regarded as the critical current of the DPC. In DPC 1 and DPC 2 , the critical current calculation error was found to be well matched with $-4.673 \mathrm{~A}$ and $0.45 \mathrm{~A}$, respectively. However, the errors of critical current, which is considered only in the perpendicular direction of magnetic field, differ greatly (48.62 A and 43.23 A, respectively). Additionally, the parts for which the minimum critical current is calculated for each SPC are compared in Table 3. Critical currents considered only in the perpendicular direction have a minimum value only in the center of the long part and the short part, whereas critical currents with all angles considered are observed in various parts. Figure 11a,b show the critical current degradation ratio for each SPC at the cross section $(z=0)$. At $70 \mathrm{~K}$, the critical current of SPC 2 is reduced the most, whereas at $40 \mathrm{~K}$, the critical current of SPC 1 is reduced the most. The calculation results show that the critical current distribution can vary depending upon the temperature range.

Table 3. Comparison of measured and calculated critical current of each DPC.

\begin{tabular}{|c|c|c|c|c|c|c|}
\hline \multirow{2}{*}{\multicolumn{2}{|c|}{ Coil }} & \multirow{4}{*}{$\begin{array}{c}\begin{array}{c}\text { Calculated } \\
\text { (with Only } B_{\perp} \text { ) }\end{array} \\
\text { 121.60 A (long) } \\
122.83 \text { A (long) }\end{array}$} & \multirow{4}{*}{$\begin{array}{c}\begin{array}{c}\text { Calculated } \\
\text { (with All Angles) }\end{array} \\
77.24 \text { A (short) } \\
68.31 \text { A (curve) }\end{array}$} & \multirow{4}{*}{$\begin{array}{c}\text { Measured } \\
72.98 \mathrm{~A}\end{array}$} & \multicolumn{2}{|c|}{ Error } \\
\hline & & & & & \multirow{3}{*}{$\begin{array}{r}\text { Only } B_{\perp} \\
48.62 \mathrm{~A}\end{array}$} & \multirow{3}{*}{$\begin{array}{l}\text { Angles } \\
-4.67 \mathrm{~A}\end{array}$} \\
\hline & SPC 1 & & & & & \\
\hline $\mathrm{DPC}$ & SPC 2 & & & & & \\
\hline \multirow{2}{*}{ DPC 2} & SPC 3 & 121.98 A (short) & 79.20 A (short) & \multirow{2}{*}{$78.75 \mathrm{~A}$} & \multirow{2}{*}{$43.23 \mathrm{~A}$} & \multirow{2}{*}{$0.45 \mathrm{~A}$} \\
\hline & SPC 4 & 128.12 A (short) & 81.82 A (short) & & & \\
\hline
\end{tabular}




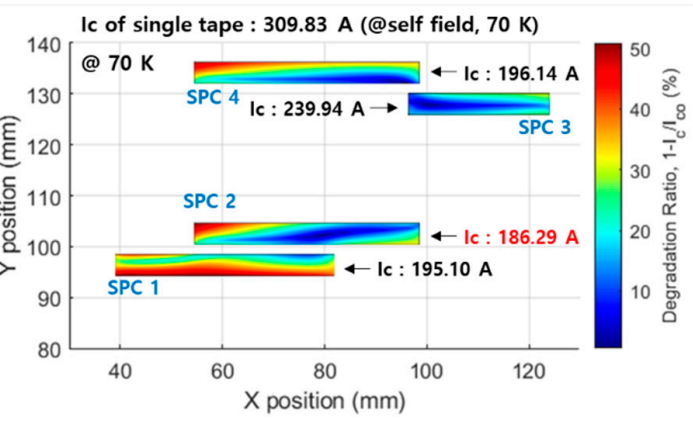

(a)

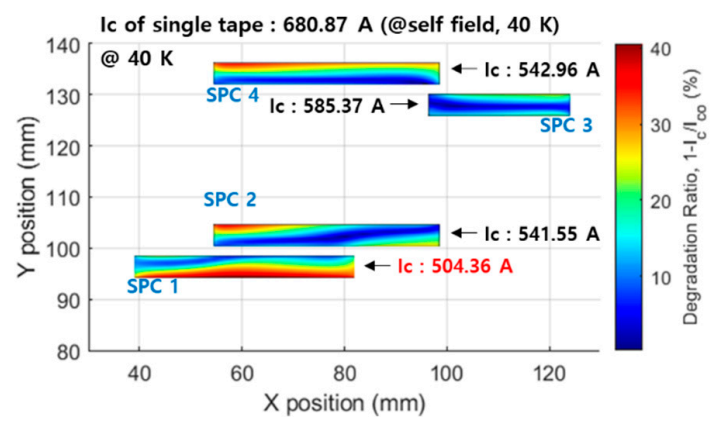

(b)

Figure 11. Calculation results of critical current degradation ratio at the cross section $(\mathrm{z}=0)$. (a) Operating temperature $=70 \mathrm{~K}$; (b) operating temperature $=40 \mathrm{~K}$.

\section{Comparison of Air-Core and Iron-Core of $9.0 \mathrm{~T} / \mathrm{m}$ HTS Quadrupole Magnet}

The prototype HTS iron-core quadrupole magnet for HQ4 in the IF separator was designed and fabricated by IBS and KERI. Prototype HTS quadrupole magnets have been reported to have been successfully fabricated and tested [6]. We designed an air-core quadrupole magnet that meets the same requirements to compare the characteristics of the air-core and iron-core models. Table 4 summarizes the design parameters of the designed air-core quadrupole magnets for a gradient of $9.0 \mathrm{~T} / \mathrm{m}$, an effective length of $550 \mathrm{~mm}$, and a uniformity of less than $1 \%$.

Table 4. Design parameters of the $9.0 \mathrm{~T} / \mathrm{m}$ air-core HTS quadrupole magnet.

\begin{tabular}{ccccccccc}
\hline Design Parameter & Unit & SPC 1 & SPC 2 & SPC 3 & SPC 4 & SPC 5 & SPC 6 & SPC 7 \\
\hline HTS tape width $\left(\mathrm{H}_{1}\right)$ & $\mathrm{mm}$ & & & & 12.1 & & & \\
SUS tape width $\left(\mathrm{H}_{2}\right)$ & $\mathrm{mm}$ & & & & 12.1 & & & \\
HTS tape thickness $\left(\mathrm{t}_{1}\right)$ & $\mathrm{mm}$ & & & & 0.1 & & & \\
SUS tape thickness $\left(\mathrm{t}_{2}\right)$ & $\mathrm{mm}$ & & & & 0.12 & & & \\
Distance from center $(\mathrm{D})$ & $\mathrm{mm}$ & 193.9 & 240.9 & 258.4 & 275.8 & 293.6 & 319.1 & 381.6 \\
Coil width $(\mathrm{W})$ & $\mathrm{mm}$ & 239.8 & 158.4 & 305.3 & 216.3 & 209.4 & 344.6 & 257.9 \\
Turns $(\mathrm{N})$ & $\mathrm{turn}$ & 300 & 300 & 300 & 300 & 300 & 300 & 209 \\
Radius of curve $\left(\mathrm{R}_{\mathrm{C}}\right)$ & $\mathrm{mm}$ & 27.1 & 25.5 & 26 & 24.6 & 28.1 & 24 & 26.9 \\
Coil length $\left(\mathrm{L}_{\mathrm{C}}\right)$ & $\mathrm{mm}$ & 480.8 & 477.6 & 554.3 & 551.5 & 489.2 & 481 & 557.3 \\
\hline
\end{tabular}

Figure 12 shows the magnetic properties of the designed air-core HTS quadrupole magnet with the operating current. The uniformity and effective length of the air-core quadrupole magnet with the iron-core removed with nonlinear magnetization characteristics do not change depending on the operating current. Then, the required field gradient can be satisfied by adjusting the operating current. The iron-core model is designed to be more than $550 \mathrm{~mm}$, because the effective length can be adjusted by the operating current. However, the air-core quadrupole magnet should be designed to meet the required effective length. Therefore, the designed air-core quadrupole magnet was set to have a field gradient of more than $9.0 \mathrm{~T} / \mathrm{m}$, an effective length of $550 \pm 1 \mathrm{~mm}$ and uniformity of less than $0.5 \%$. Uniformity, which does not change with the current of air-core quadrupole magnet, is set to be lower than the requirements in consideration of manufacturing errors. Table 5 summarizes the specifications designed for HQ4 of the IF separator. The designed air-core quadrupole magnets met all the required magnetic field properties. 


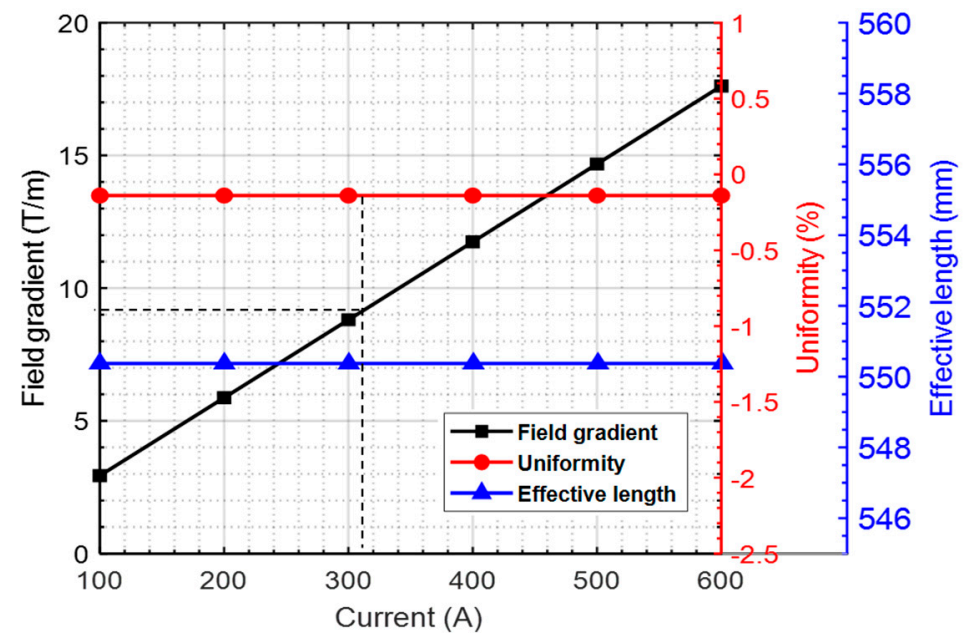

Figure 12. Magnetic field properties of the designed air-core HTS quadrupole magnet with respect to operating current.

Table 5. Specifications of the HTS quadrupole magnets for HQ4 of the in-flight fragment (IF) separator.

\begin{tabular}{ccccc}
\hline Name & Reference Radius & Field Gradient & Effective Length & Uniformity \\
\hline Required specifications & $150 \mathrm{~mm}$ & $9.0 \mathrm{~T} / \mathrm{m}$ & $550 \mathrm{~mm}$ & $<1$ \\
Set target for air-core & $150 \mathrm{~mm}$ & $>9.0 \mathrm{~T} / \mathrm{m}$ & $550 \pm 1 \mathrm{~mm}$ & $<0.5$ \\
Design results & $150 \mathrm{~mm}$ & $9.1019 \mathrm{~T} / \mathrm{m}$ & $550.4 \mathrm{~mm}$ & $-0.1393\left(\mathrm{U}_{6}\right)$ \\
& & & $-0.2555\left(\mathrm{U}_{10}\right)$ \\
\hline
\end{tabular}

Additionally, the magnetic field of the iron-core quadrupole magnet was extracted and the maximum von Mises stress of the two models was compared by the finite element method (FEM). For this FEM analysis, the design parameters of the $9.0 \mathrm{~T} / \mathrm{m}$ iron-core quadrupole magnet were used, as reported previously [7]. Figure 13a shows the calculated magnetic field of the iron-core quadrupole magnet, and Figure 13b,c show the Lorentz force and von Mises stress calculation results for the iron-core and the designed air-core quadrupole magnet. Several characteristics, including von Mises stress and critical currents of the air-core and iron-core quadrupole magnets, are compared in Table 6.

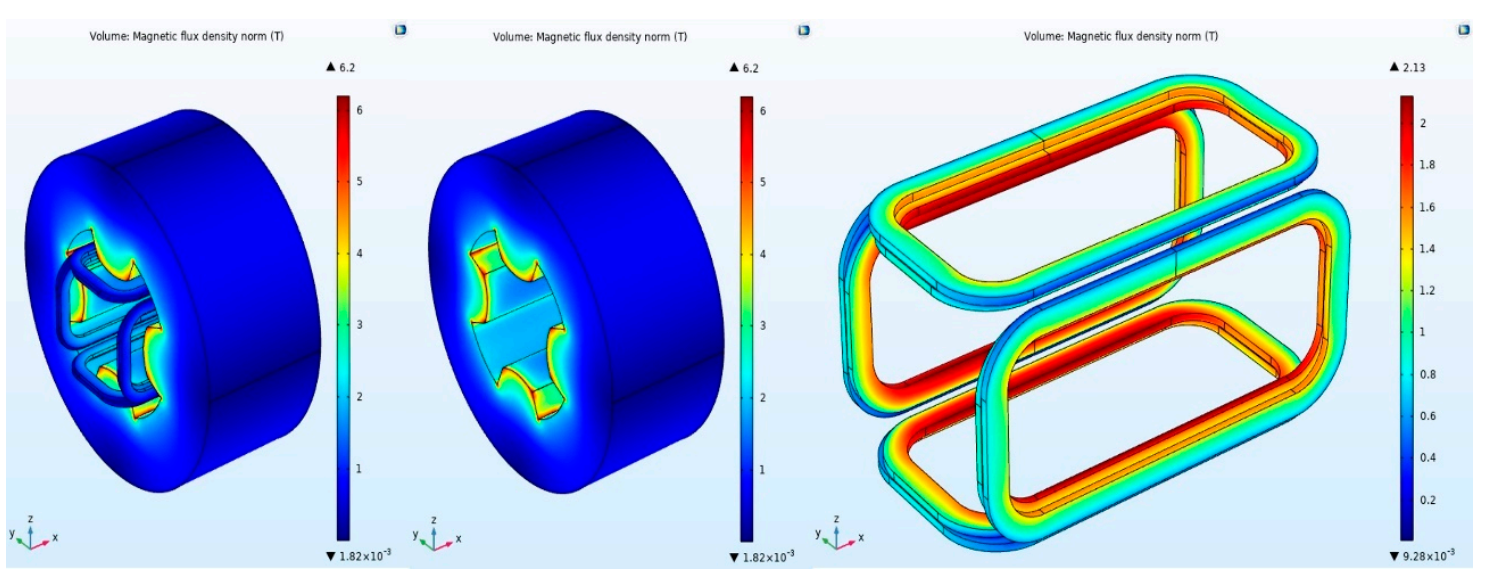

(a)

Figure 13. Cont. 


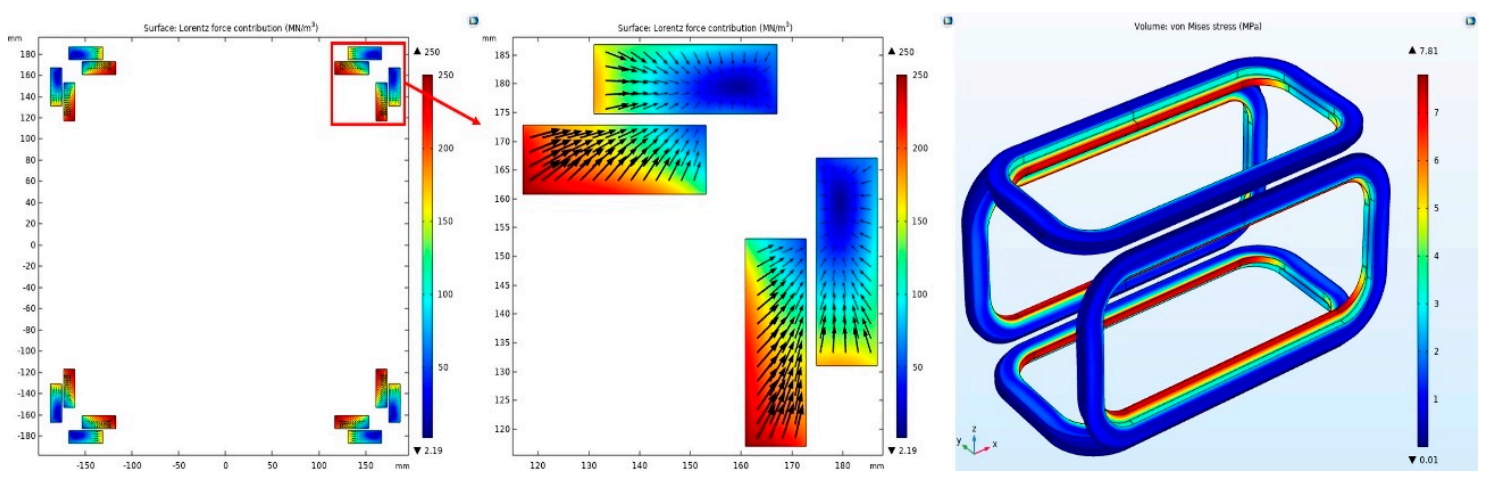

(b)
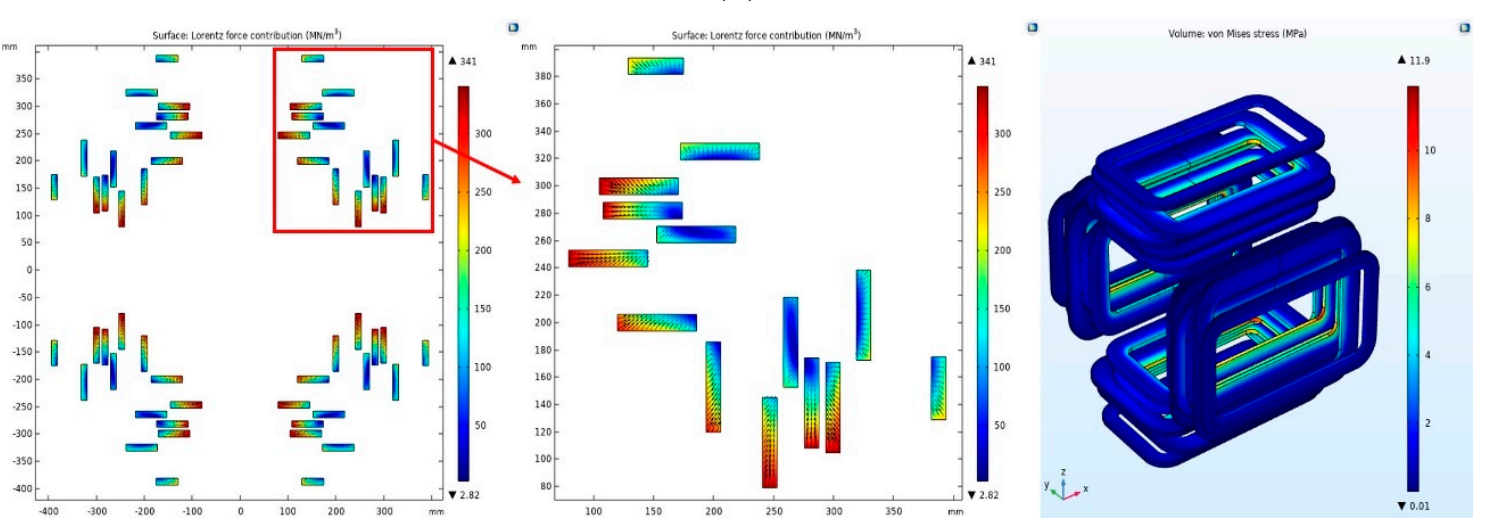

(c)

Figure 13. Finite element method (FEM) analysis results for the air-core and iron-core HTS quadrupole magnet. (a) Calculation result of the magnetic flux density of iron-core and HTS coil; (b) Lorentz force and von Mises stress calculation results of HTS coil in the iron-core model; (c) Lorentz force and von Mises stress calculation results of HTS coil in the air-core model.

Table 6. Comparison of the air-core model with the iron-core model.

\begin{tabular}{cccc}
\hline Parameters & Unit & Air-Core & Iron-Core \\
\hline Operating current & $\mathrm{A}$ & 310 & 310 \\
Field gradient & $\mathrm{T} / \mathrm{m}$ & 9.1019 & 9.0 \\
6th Uniformity & $\%$ & -0.1393 & 0.5 \\
10th Uniformity & $\%$ & -0.2555 & 0.01 \\
Effective length & $\mathrm{mm}$ & 550.4 & 564 \\
Pole tip field of iron yoke & $\mathrm{T}$ & 0 & 1.52 \\
Volume of iron yoke & $\mathrm{mm}^{3}$ & 0 & $3.0919 \times 10^{8}$ \\
Weight of iron yoke & $\mathrm{kg}$ & 0 & 2430 \\
Maximum perpendicular field on HTS tape & $\mathrm{T}$ & 1.85 & 1.52 \\
Maximum parallel field on HTS tape & $\mathrm{T}$ & 3.41 & 1.93 \\
$\mathrm{I}_{\mathrm{C}}$ at 40 K (using tape I I 831 A @ s.f, $\left.77 \mathrm{~K}\right)$ & $\mathrm{A}$ & 317.83 & 428.46 \\
Volume of HTS tape & $\mathrm{mm}$ & $35.785 \times 10^{6}$ & $5.8271 \times 10^{6}$ \\
Weight of HTS tape & $\mathrm{kg}$ & 292.72 & 47.67 \\
Total length of HTS tape & $\mathrm{km}$ & 13.443 & 2.207 \\
Length of coil & $\mathrm{mm}$ & 686.3 & 660.16 \\
Maximum Lorenz force of coil & $\mathrm{MN} / \mathrm{mm}^{3}$ & 341 & 250 \\
Maximum von Mises stress of coil & $\mathrm{MPa}$ & 11.9 & 7.81 \\
\hline
\end{tabular}

The field gradient, effective length, and uniformity of the two models with the same operating current of $310 \mathrm{~A}$ are designed to meet the required specifications of HQ4. In the iron-core model, the pole tip field of the iron yoke is $1.52 \mathrm{~T}$, which is not significantly greater than the magnetic field generated inside the HTS tapes. Because the air-core model does not contain an iron yoke, there is 
no magnetic field in the yoke, and the air-core does not include the volume and weight of the iron yoke. The air-core quadrupole magnet has an additional $11.236 \mathrm{~km}$ of HTS wire compared with the iron-core model, which adds an additional weight of $245.05 \mathrm{~kg}$. However, because an iron yoke is not used, the air-core model can be made lighter at $2184.95 \mathrm{~kg}$. The maximum Lorenz force of the air-core model and the iron-core model is calculated at $341,250 \mathrm{MN} / \mathrm{mm}^{3}$, respectively, and the maximum von Mises stress of the coil in the air-core model is $4.09 \mathrm{MPa}$ higher than that of the iron-core model. The yield stress of an HTS coil containing co-winded stainless steel (AISI 304) as insulation is estimated to be $400 \mathrm{MPa}$ [9]. Therefore, both models have enough margin for the yield strength of the HTS coil. The maximum perpendicular magnetic field applied to the HTS tape differs by $0.33 \mathrm{~T}$, but the maximum parallel magnetic field applied to the HTS tape is $3.41 \mathrm{~T}$ (about 1.77 times stronger than the iron-core model). Among the compared parameters, the difference in critical current because of the large magnetic field of the air-core is noted. For critical current calculations, HTS tapes with a critical current of $831 \mathrm{~A}$ were used when magnetic fields were not applied at $77 \mathrm{~K}$. The critical currents of the air-core model and the iron-core model, calculated at $40 \mathrm{~K}$, were $317.83 \mathrm{~A}$ and $428.46 \mathrm{~A}$, respectively. It has been reported that the critical current of the superconducting wire is reduced by approximately $20 \%$ after an exposure to 100 MGy radiation [2,21]. Therefore, the air-core model using HTS tape with a critical current of $831 \mathrm{~A}$ lacks the margin for an operating current of $310 \mathrm{~A}$ after exposure to radiation. For the higher capacity air-core HTS quadrupole magnet, the shape design to increase the critical current is introduced in Section 5.

\section{Optimum Shape Design to Minimize $I_{C}$ Degradation by the Incident Magnetic Field}

\subsection{Optimization Algorithm for Air-Core Quadrupole Magnet Design}

The air-core HTS quadrupole magnet consisting of seven SPCs in one pole has 35 design variables (5 variables per SPC). Additionally, six parameters- $\mathrm{G}, \mathrm{L}_{\mathrm{eff}}, \mathrm{U}_{6}, \mathrm{U}_{10}$, length of HTS tape ( $\mathrm{L}_{\mathrm{HTS}}$ ) and $\mathrm{I}_{\mathrm{C}}$-were evaluated for optimal design. Finding the best combination of variables while increasing or decreasing all variables takes a considerable amount of time. Therefore, appropriate optimization algorithms should be used. In this study, one of the optimization methods, the genetic algorithm (GA), was used for the optimal design of the air-core quadrupole magnet. GA is a probability-based algorithm, and many studies have demonstrated that it can effectively find the global optimum without converging to the local optimum in complex nonlinear problems [22-24]. GA imitates the evolutionary process of nature, in which objects selected from the population are bred and mutated, resulting in better populations surviving in the next generation.

Figure 14 shows the optimal design process using GA. At the beginning of the process, 40 initial populations with 35 variables are created, and the constraints are evaluated first. Constraints were set up to be examined for interference between each SPC. The combination of variables that does not meet the constraint is modified into appropriate variables and used for parent generation. After calculating the six design factors of 40 shapes, the value of the objective function (OF) with the weight factor is calculated. Each combination of variables is then assigned a fitness, so that more objects with smaller OF values can be selected. Thus, each OF was set to have a smaller value as it approached the desired design goal. The OF for the six parameters was set using Equations (11)-(17). The field gradient and effective length were set to have a smaller OF value as they approached the target value. Additionally, the uniformity and length of the HTS tape were set to have smaller OF values, as the calculated values are smaller. The specifications of $\mathrm{G}, \mathrm{L}_{\mathrm{eff}}$ and $\mathrm{U}$ were set by dividing the weight factor, so that no smaller value was found within the target range. The weight factor applied to each OF is represented by Equations (18)-(23). The weight factor of the critical current, $\mathrm{K}_{6}$, was set as a negative number, so that the greater the critical current, the smaller the OF value. 


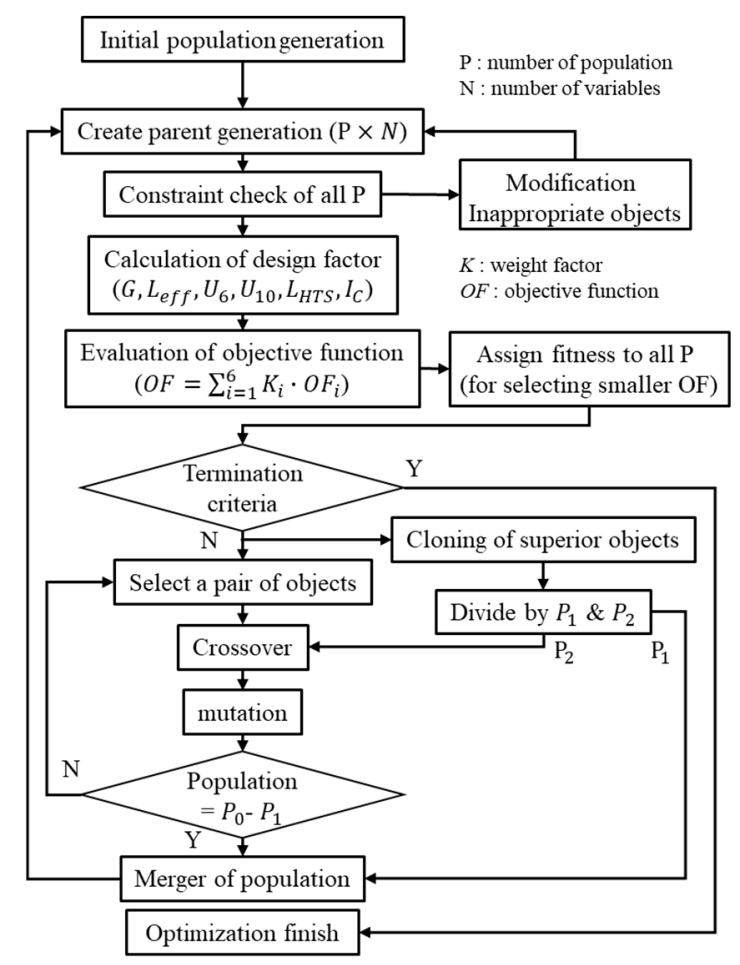

Figure 14. Optimization design process using the genetic algorithm (GA).

To eliminate interference between SPCs, all seven D values (distance from center) were reconstructed with one $\mathrm{D}_{1}$ for the innermost SPC and six g (gap between SPCs). Equation (24) was also used as a constraint to avoid interference between neighboring poles. This constraint ensures that the boundaries of neighboring poles and the SPC are more than $1 \mathrm{~cm}$ apart. Additionally, the magnitude of each weight factor was set for faster convergence in consideration of the values of the respective OFs calculated. Additionally, to improve the convergence speed of GA, the method that uses the best performing shapes in the next generation without going through other processes was used.

$$
\begin{gathered}
O F=K_{1} \cdot O F_{1}+K_{2} \cdot O F_{2}+K_{3} \cdot O F_{3}+K_{4} \cdot O F_{4}+K_{5} \cdot O F_{5}+K_{6} \cdot O F_{6} \\
O F_{1}=\left|G_{\text {target }}-G\right| / G_{\text {target }} \\
O F_{2}=\left|L_{e f f, \text { target }}-L_{e f f}\right| / L_{\text {eff,target }} \\
O F_{3}=\left|U_{6}\right| \\
O F_{4}=\left|U_{10}\right| \\
O F_{5}=\left|L_{H T S}\right| \\
O F_{6}=I_{C} \\
K_{1}=\left\{\begin{array}{c}
0, \text { if }\left|G_{\text {target }}-G\right|<\left(G_{\text {target }} \cdot 5 / 1000\right) \\
800, \text { else }
\end{array}\right. \\
K_{2}=\left\{\begin{array}{c}
0, \text { if }\left|L_{\text {eff,target }}-L_{\text {eff }}\right|<1 \mathrm{~mm} \\
300, \text { else }
\end{array}\right. \\
K_{3}=\left\{\begin{array}{c}
0, \text { if }\left|U_{6, \text { target }}-U_{6}\right|<0.5 \% \\
80, \text { else }
\end{array}\right.
\end{gathered}
$$




$$
\begin{gathered}
K_{4}=\left\{\begin{array}{c}
0, \text { if }\left|U_{10, \text { target }}-U_{10}\right|<0.5 \% \\
120, \text { else }
\end{array}\right. \\
K_{5}=300 \\
K_{6}=-2 \\
W+N \cdot\left(t_{1}+t_{2}\right)+0.01<D
\end{gathered}
$$

\subsection{Optimization Result}

Table 7 summarizes the designed parameters of shape that show the lowest $\mathrm{I}_{C}$ reduction while meeting all design requirements. The design variables for each SPC were set to $D, W, N, R_{C}$ and $L_{C}$, and all parameters except the turn of SPC 6 determined the optimal value within the set boundary conditions of the variables. For ease of actual fabrication, the maximum boundary for the number of turns was set to 300 turns that can be manufactured.

Table 7. Design parameters of the $9.0 \mathrm{~T} / \mathrm{m}$ air-core HTS quadrupole magnet.

\begin{tabular}{ccccccccc}
\hline Design Parameter & Unit & SPC 1 & SPC 2 & SPC 3 & SPC 4 & SPC 5 & SPC 6 & SPC 7 \\
\hline HTS tape width $\left(\mathrm{H}_{1}\right)$ & $\mathrm{mm}$ & & & & 12.1 & & & \\
SUS tape width $\left(\mathrm{H}_{2}\right)$ & $\mathrm{mm}$ & & & & 12.1 & & & \\
HTS tape thickness $\left(\mathrm{t}_{1}\right)$ & $\mathrm{mm}$ & & & & 0.1 & & & \\
SUS tape thickness $\left(\mathrm{t}_{2}\right)$ & $\mathrm{mm}$ & & & & 0.12 & & & \\
Distance from center $(\mathrm{D})$ & $\mathrm{mm}$ & 180.3 & 225.6 & 247.0 & 264.5 & 295.1 & 320.8 & 365.2 \\
Coil width $(\mathrm{W})$ & $\mathrm{mm}$ & 215.1 & 96.4 & 354.3 & 338.0 & 206.9 & 448.5 & 378.9 \\
Turns $(\mathrm{N})$ & $\mathrm{turn}$ & 285 & 251 & 264 & 287 & 287 & 300 & 243 \\
Radius of curve $\left(\mathrm{R}_{\mathrm{C}}\right)$ & $\mathrm{mm}$ & 26.1 & 26.5 & 27.9 & 30.3 & 30.7 & 31.2 & 27.2 \\
Coil length $\left(\mathrm{L}_{\mathrm{C}}\right)$ & $\mathrm{mm}$ & 477.6 & 516.5 & 551.3 & 490.9 & 558.5 & 539.1 & 483.8 \\
\hline
\end{tabular}

Figure 15a,b show the calculated magnetic field patterns of the initial model (case \#1) and the optimized model (case \#2) at $\mathrm{z}=0$, which is the center of the beam transporting direction. The magnetic field patterns at the reference radius $(R=150)$ of case \#1 and case \#2 are similar, but the magnetic field patterns inside the coils are different. In case \#2, the maximum magnetic flux density norm was $2.4683 \mathrm{~T}$, which is approximately $15 \%$ less than case \#1, as the coil was positioned close to the adjacent pole, and the offset magnetic field increased.

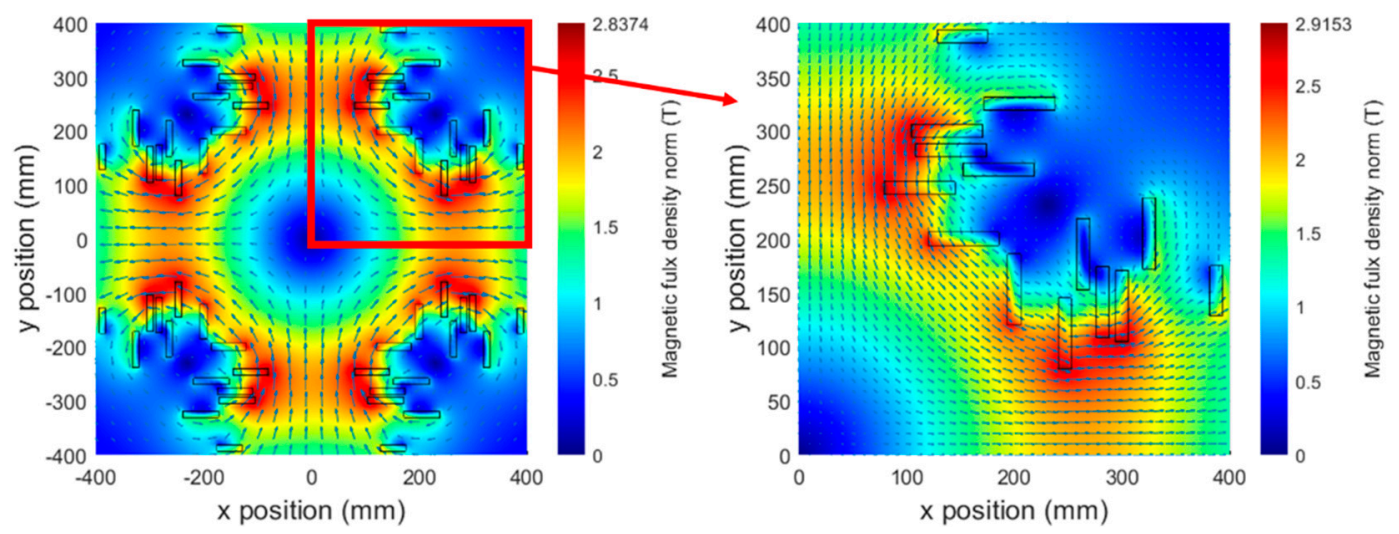

(a)

Figure 15. Cont. 


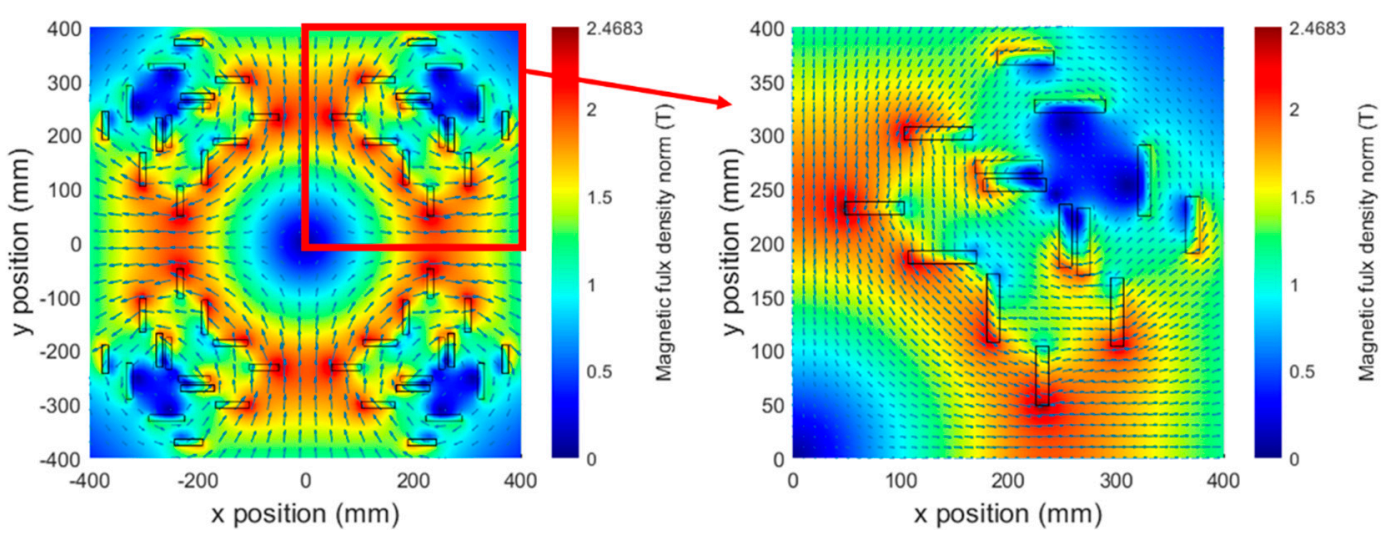

(b)

Figure 15. Comparison of magnetic field patterns at the cross section $(z=0)$. (a) case \#1; (b) case \#2.

Figure 16a shows the field gradient and the 6th and 10th harmonics along the beam direction in the case \#2 geometry. The second harmonics at position $\mathrm{z}=0$ is $1.3517 \mathrm{~T}$, and the field gradient at a reference radius of $150 \mathrm{~mm}$ was calculated to be $9.011 \mathrm{~T} / \mathrm{m}$. The uniformities calculated from each harmonic are shown in Figure 16b. The uniformity was the highest in the 6th and 10th order, and some 12 th order components were generated. All uniformities were rated within $0.5 \%$ of the design target.

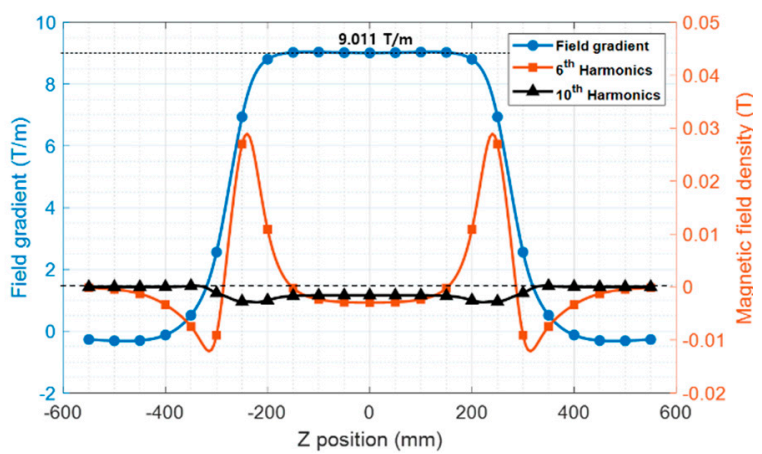

(a)

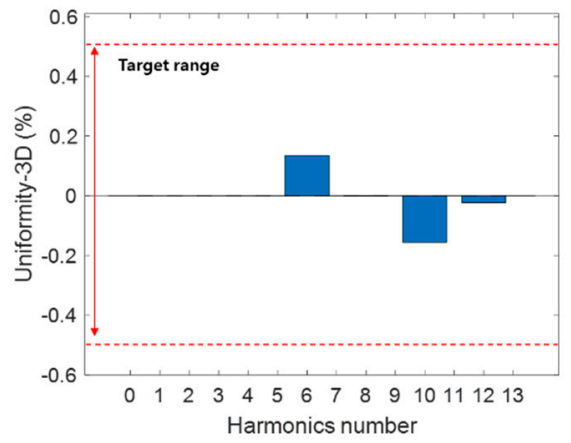

(b)

Figure 16. (a) Magnetic field characteristics along the $\mathrm{z}$ direction of case \#2; (b) Uniformity calculated for each harmonic number.

Table 8 summarizes the magnetic properties calculated using the optimally designed case \#2 geometry. All magnetic properties of the designed case \#2 meet the set design target.

Table 8. Magnetic field properties of the optimally designed case \#2.

\begin{tabular}{ccccc}
\hline Name & Reference Radius & Field Gradient & Effective Length & Uniformity \\
\hline Required specifications & $150 \mathrm{~mm}$ & $9.0 \mathrm{~T} / \mathrm{m}$ & $550 \mathrm{~mm}$ & $<1$ \\
Set target for air-core & $150 \mathrm{~mm}$ & $9.005 \sim 9.095 \mathrm{~T} / \mathrm{m}$ & $549 \sim 551 \mathrm{~mm}$ & $<0.5$ \\
Design results & $150 \mathrm{~mm}$ & $9.011 \mathrm{~T} / \mathrm{m}$ & $549.82 \mathrm{~mm}$ & $0.1349\left(\mathrm{U}_{6}\right)$ \\
& & & & $-0.1563\left(\mathrm{U}_{10}\right)$ \\
\hline
\end{tabular}

In case \#2, the areas with the lowest critical current from SPC 1 to SPC 7 were calculated to be long, short, curved, short, short, short and curved, respectively. Additionally, among the seven SPCs, SPC 1 was calculated to have the largest critical current degradation. The case \#1 was also calculated to have the short region of SPC 1 where the critical current was greatly reduced. In both cases, the lowest critical current was calculated at the $\mathrm{z}=0$ position of SPC 1 . Figure $17 \mathrm{a}, \mathrm{b}$ compare the degradation ratio patterns of case $\# 1$ and case $\# 2$ calculated at $\mathrm{z}=0$. 


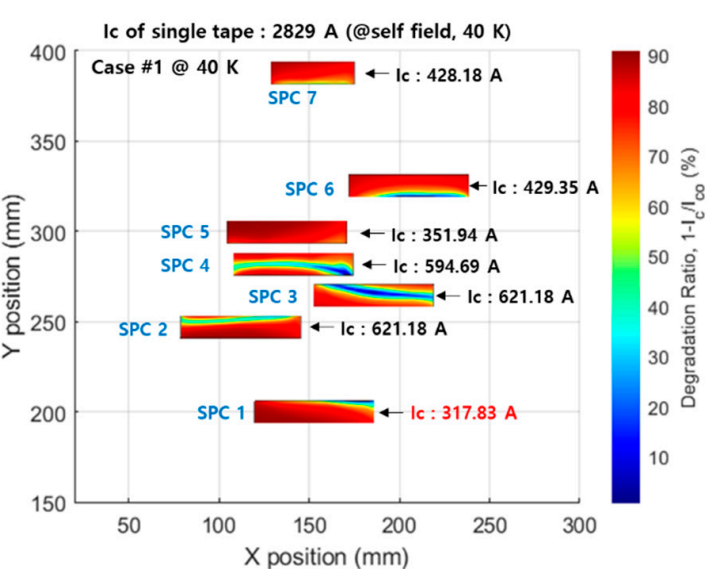

(a)

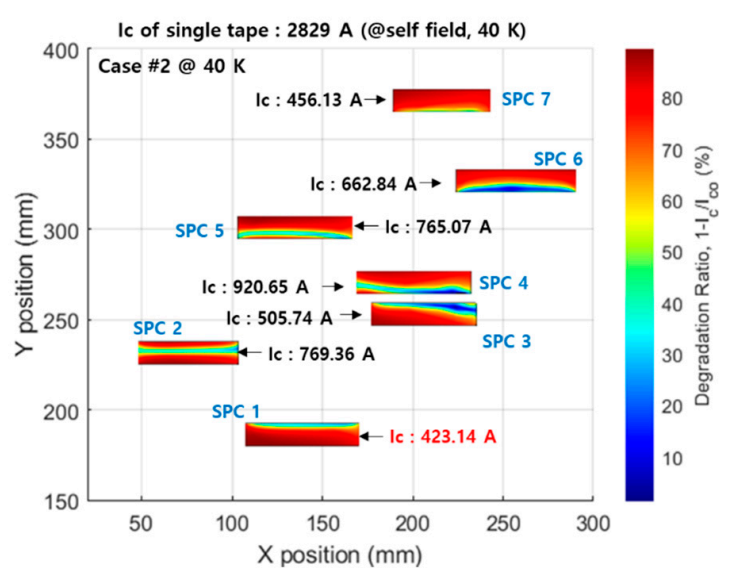

(b)

Figure 17. Calculation results of critical current degradation ratio at the $\mathrm{z}=0$ position. (a) Early shape (case \#1); (b) Optimized shape (case \#2).

The critical current was calculated at an operating temperature of $40 \mathrm{~K}$, and HTS tape with a critical current of 2829 A was used when the magnetic field was not applied. Compared to case \#1, case \#2 showed an increased critical current in all SPCs except SPC 3. Additionally, the lowest critical current of SPC 1, which is evaluated as the critical current of the quadrupole magnet, increased from 317.83 A to $423.14 \mathrm{~A}$.

Figure 18 compares the critical current for each operation current of the iron-core model and the two cases of air-core models. At $40 \mathrm{~K}$, the critical current of case \#1 had a small margin, while the critical current of case \#2 with the optimal design increased to $423.14 \mathrm{~A}$, similar to the $\mathrm{I}_{\mathrm{C}}$ of the air-core model. The operating current to satisfy $9.0 \mathrm{~T} / \mathrm{m}$ was $310 \mathrm{~A}$, and at $40 \mathrm{~K}$, case \#1 had a safety margin of approximately $2.5 \%$, whereas case \#2 had a safety margin of approximately $27 \%$. Additionally, considering the temperature rise of the HTS coil due to radiation heating, the iron-core model, air-core model (case \#1) and air-core model (case \#2) have temperature margins of 7.4, 0.6 and $6.6 \mathrm{~K}$, respectively.

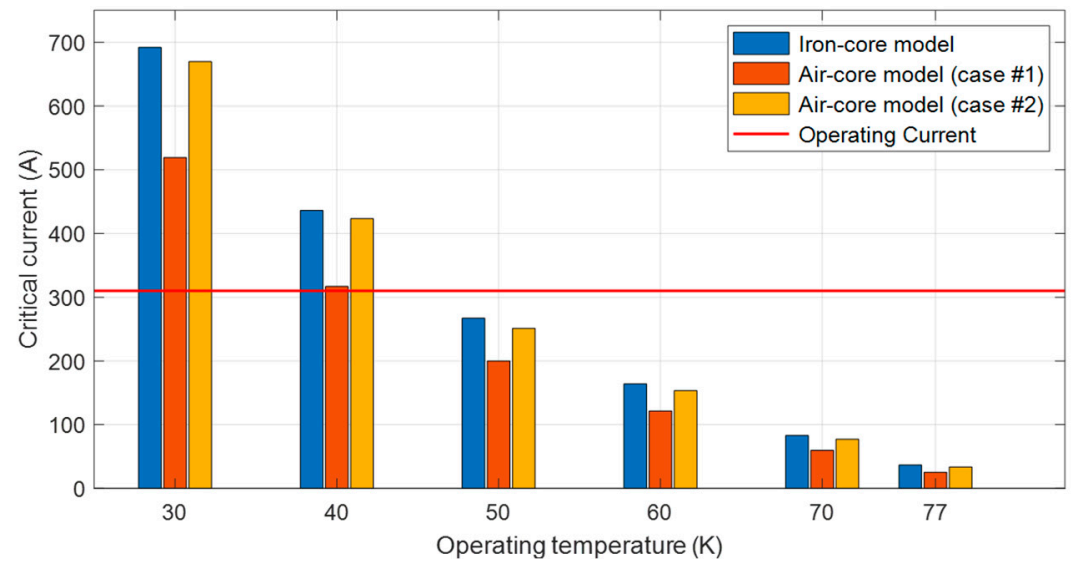

Figure 18. Critical current for each operation current of the iron-core model and the two cases of air-core models.

\section{Conclusions and Discussion}

In this study, we fabricated a $3.0 \mathrm{~T} / \mathrm{m}$ air-core HTS quadrupole magnet, and measured the magnetic field properties to validate the air-core HTS quadrupole magnet with HTS tape and with its iron-core removed. We confirmed that the measured magnetic field properties meet the desired ones. We also designed an air-core model to meet the requirements of HQ4, which will be installed at the front end of IF of RAON, to evaluate the availability of the air-core HTS quadrupole magnet in the actual accelerator 
capacity. Additionally, the magnetic field properties, volume, weight, maximum magnetic field, critical current, Lorenz force and mechanical stress of the $9.0 \mathrm{~T} / \mathrm{m}$ air-core model and the iron-core model were compared. Compared to the iron-core model, the air-core model uses more HTS wires without the use of iron; however, the removal of iron can make it $88.19 \%$ lighter than the iron-core model. We confirmed that both models could be designed to meet the required magnetic field properties. Moreover, we confirmed that the uniformity and effective length of the air-core model do not change with the magnitude of the operating current, because the air-core model does not use iron with nonlinear magnetization characteristics. However, there is a linearly proportional relationship between the operating current and the field gradient. Therefore, the air-core model can meet the desired field gradient without changing other magnetic field properties by adjusting the operating current.

Notably, the air-core model with the iron-core removed significantly reduced the critical current, because a stronger magnetic field was applied to the HTS tape. Therefore, we propose a calculation method that considers the critical current data measured from all angles for the accurate prediction of the critical current, and compares it with the critical current measurement results of the two DPCs fabricated to ensure the reliability of the critical current calculation. Therefore, we proposed a calculation method that considers the reduction of the critical current at all angles for the accurate prediction of the critical current. To ensure the reliability of the critical current calculation, the critical currents of the two DPCs were measured and compared with the calculation results. The critical current calculation results were found to agree well with the experimental results. We also introduced an optimization process using GA to increase the critical current. The optimally designed air-core HTS quadrupole magnet in case \#2 satisfied all required magnetic field properties, while increasing the critical current by approximately $33 \%$. The increased critical current was similar to that of the iron-core model, and a safety margin of approximately $27 \%$ was confirmed to be obtained at an operating temperature of $40 \mathrm{~K}$. HTS tape with higher $\mathrm{I}_{\mathrm{C}}$ or HTS tape with good performance for the applied magnetic field can be used to increase the critical current, but these models can be more expensive to manufacture. Additionally, for higher capacity air-core models, the geometry of reducing the critical current reduction can be considered simultaneously with this method. Additionally, for the higher capacity air-core model, the critical current reduction can be considered simultaneously with the alternative to other HTS tapes. Consequently, the optimal shape to reduce the critical current degradation can be expected to be applied to the design of air-core models because of several advantages over the iron-core to secure a higher safety margin.

However, since the air-core model cannot adjust the field uniformity and effective length by the operating current, the air-core quadrupole magnet should minimize factors, such as the manufacturing error that can cause a difference in the design requirements. In the next study, we will conduct a study to apply the magnetic field shimming method to adjust the field uniformity and effective length of the air-core quadrupole magnet that does not change with the operating current.

Author Contributions: Conceptualization, Y.C.; methodology, Y.C., J.K., and W.S.L.; software, Y.C. and S.H.; validation, G.B. and W.S.L.; formal analysis, Y.C.; investigation, G.B. and S.H.; resources, T.K.K.; data curation, Y.C.; writing - original draft preparation, Y.C.; supervision, T.K.K.; funding acquisition, T.K.K. All authors have read and agreed to the published version of the manuscript.

Funding: This research was supported in part by Korea Electric Power Corporation. (Grant number: R17XA05_32). This work was supported in part by "Human Resources Program in Energy Technology" of the Korea Institute of Energy Technology Evaluation and Planning (KETEP), granted financial resource from the Ministry of Trade, Industry and Energy, Republic of Korea. (No. 20184030202270).

Conflicts of Interest: The authors declare no conflict of interest. 


\section{References}

1. Kusaka, K.; Kubo, T.; Yano, Y.; Kakutani, N.; Ohsemochi, K.; Kuriyama, T.; Tsuchihashi, T.; Sato, K. An air-core type superconducting quadrupole triplet for the BigRIPS separator at RIKEN. IEEE Trans. Appl. Supercond. 2008, 18, 240-243. [CrossRef]

2. Gupta, R.; Anerella, M.; Cozzolino, J.; Ganetis, G.; Ghosh, A.; Greene, G.; Sampson, W.; Shiroyanagi, Y.; Wanderer, P.; Zeller, A. Second generation HTS quadrupole for FRIB. IEEE Trans. Appl. Supercond. 2011, 21, 1888-1891. [CrossRef]

3. Gupta, R.; Anerella, M.; Harrison, M.; Sampson, W.; Schmalzte, J.; Ronningen, R.; Zeller, A. Radiation resistant HTS quadrupoles for RIA. IEEE Trans. Appl. Supercond. 2005, 15, 1148-1151. [CrossRef]

4. Park, H.; Sim, K.; Jo, H.; Kim, D.G.; Kim, J.; Kim, S. Thermal and Mechanical Design of a HTS Quadrupole Magnet of In-Flight Fragment Separator for Rare Isotope Science Project (RISP). IEEE Trans. Appl. Supercond. 2016, 26, 4601404. [CrossRef]

5. Gupta, R.; Anerella, M.; Cozzolino, J.; Joshi, P.; Sampson, W.; Wanderer, P.; Zeller, A. HTS quadrupole for FRIB-Design, construction and test results. IEEE Trans. Appl. Supercond. 2015, 25, 4603306. [CrossRef]

6. Jo, H.C.; Kim, D.G.; Choi, S.; Jang, H.M.; Sim, K.; Kim, S. Prototype HTS Quadrupole Magnet for the In-Flight Fragment Separator of RISP. IEEE Trans. Appl. Supercond. 2018, 28, 4008906. [CrossRef]

7. Choi, J.; Lee, S.; Lee, C.K.; Kim, D.G.; Park, M.; Sim, K. Electromagnetic design of consecutive HTS quadrupole magnets for the preseparator at RISP. IEEE Trans. Appl. Supercond. 2018, 28, 1-6. [CrossRef]

8. Zhang, Z.; Wei, S.; Lee, S. Design of an Air-Core HTS quadruple triplet for a heavy ion accelerator. Prog. Supercond. Cryog. 2016, 18, 35-39. [CrossRef]

9. Kim, J.; Baek, G.; Lee, J.; Choi, Y.; Han, S.; Song, S.; Ko, T.K. Analysis of magnetic field harmonics change due to manufacturing error in air-core HTS quadruple magnet. Cryogenics 2019, 98, 39-46. [CrossRef]

10. Lee, J.; Kim, J.; Baek, G.; Choi, Y.; Choi, Y.H.; Zhang, Z.; Do Chung, Y.; Kang, H.; Lee, H.; Lee, S.; et al. Comparative Study of Magnetic Characteristics of Air-Core and Iron-Core High-Temperature Superconducting Quadrupole Magnets. IEEE Trans. Appl. Supercond. 2018, 28, 1-5. [CrossRef]

11. Turrioni, D.; Barzi, E.; Lamm, M.J.; Yamada, R.; Zlobin, A.V.; Kikuchi, A. Study of HTS wires at high magnetic fields. IEEE Trans. Appl. Supercond. 2009, 19, 3057-3060. [CrossRef]

12. Igarashi, M.; Nakao, H.; Terai, M.; Kuriyama, T.; Hanai, S.; Yamashita, T.; Yamaji, M. Persistent current HTS magnet cooled by cryocooler (1)-project overview. IEEE Trans. Appl. Supercond. 2005, 15, 1469-1472. [CrossRef]

13. Snitchler, G.; Kalsi, S.S.; Manlief, M.; Schwall, R.E.; Sidi-Yekhlef, A.; Ige, S.; Medeiros, R.; Francavilla, T.L.; Gubser, D.U. High-field warm-bore HTS conduction cooled magnet. IEEE Trans. Appl. Supercond. 1999, 9, 553-558. [CrossRef]

14. Wang, Q.; Song, S.; Lei, Y.; Dai, Y.; Zhang, B.; Wang, C.; Lee, S.; Kim, K. Design and fabrication of a conduction-cooled high temperature superconducting magnet for $10 \mathrm{~kJ}$ superconducting magnetic energy storage system. IEEE Trans. Appl. Supercond. 2006, 16, 570-573. [CrossRef]

15. Kim, D.; Kim, S.; Sohn, M.H.; Sim, K.; Kim, D.G.; Kim, J. Test Results of Gas-Cooled Prototype Magnet for In-Flight Fragment Separator. IEEE Trans. Appl. Supercond. 2016, 26, 3701304. [CrossRef]

16. Senatore, C.; Barth, C.; Bonura, M.; Kulich, M.; Mondonico, G. Field and temperature scaling of the critical current density in commercial REBCO coated conductors. Supercond. Sci. Technol. 2016, 29. [CrossRef]

17. Lee, K.; Sim, K.; Lee, C.; Kim, S. Estimation of the critical current of race-track HTS magnet considering angular dependency. Prog. Supercond. Cryog. 2015, 17, 47-50. [CrossRef]

18. Matsumoto, K.; Horide, T.; Osamura, K.; Mukaida, M.; Yoshida, Y.; Ichinose, A.; Horii, S. Enhancement of critical current density of YBCO films by introduction of artificial pinning centers due to the distributed nano-scaled Y $2 \mathrm{O} 3$ islands on substrates. Phys. C Supercond. 2004, 412, 1267-1271. [CrossRef]

19. Matsumoto, K.; Mele, P. Artificial pinning center technology to enhance vortex pinning in YBCO coated conductors. Supercond. Sci. Technol. 2010, 23, 014001. [CrossRef]

20. Takeda, H.; Kubo, T.; Kusaka, K.; Suzuki, H.; Inabe, N.; Nolen, J.A. Extraction of 3D field maps of magnetic multipoles from 2D surface measurements with applications to the optics calculations of the large-acceptance superconducting fragment separator BigRIPS. Nucl. Instrum. Methods Phys. Res. Sect. B Beam Interact. Mater. At. 2013, 317, 798-809. [CrossRef] 
21. Greene, G.A.; Gupta, R.C.; Sampson, W.B.; Snead, C.L. The effect of proton irradiation on the critical current of commercially produced YBCO conductors. IEEE Trans. Appl. Supercond. 2009, 19, 3164-3167. [CrossRef]

22. Saleh, R.A.F.; Bolton, H.R. Genetic algorithm-aided design of a fuzzy logic stabilizer for a superconducting generator. IEEE Trans. Power Syst. 2000, 15, 1329-1335. [CrossRef]

23. Sim, D.J.; Jung, H.K.; Hahn, S.Y.; Won, J.S. Application of vector optimization employing modified genetic algorithm to Permanent Magnet Motor design. IEEE Trans. Magn. 1997, 33, 1888-1891.

24. Kim, J.; An, S.C.; Choi, Y.; Ko, T.K.; Chu, Y. Study on Quench Detection of the KSTAR PF Coils Using Numerical Compensation of Inductive Voltages with Genetic Algorithm. IEEE Trans. Appl. Supercond. 2017, 27, 1-5. [CrossRef]

(C) 2020 by the authors. Licensee MDPI, Basel, Switzerland. This article is an open access article distributed under the terms and conditions of the Creative Commons Attribution (CC BY) license (http://creativecommons.org/licenses/by/4.0/). 